\title{
DES PIÈCES REPRÉSENTANT LES INSIGNES ET LES VÊTEMENTS LITURGIQUES COPTES CONSERVÉS DANS LES MUSÉES ARCHÉOLOGIQUES D'EGYPTE
}

\author{
Mary Magdy Anwar \\ Maître de conférences à la faculté de Tourisme et d'Hôtellerie \\ Université d'Alexandrie, Section Guide
}

Les musées internationaux et égyptiens possèdent de nombreux tissus égyptiens coptes qui remontent aux premières ères chrétiennes. Ces tissus ont presque conservé leur état grâce au climat modéré sec de l'Egypte. 1 Les Egyptiens ont toujours excellé dans la fabrication du textile. Cette célébrité demeure depuis la période pharaonique et jusqu'à l'ère islamique.

Le tissu copte a été dénommé "Kapaty- tapisserie", appellation attribuée par les Arabes, et a été le premier essai d'étoffes ornées composées de deux ou de plusieurs couleurs. 2

Parmi divers types de textiles coptes bien connus, on trouve des vêtements complets surtout des tuniques ou des parties de vêtements, des rideaux, des coussins, des nattes ainsi que des costumes religieux qui ont subi des changements à travers les siècles. 3

Les recherches prennent d'habitude en considération l'importance des tissus coptes sans mentionner en particulier les vêtements liturgiques.

Notre recherche n'est pas un traité sur l'histoire du vêtement liturgique ni une analyse de la garde-robe du clergé copte. Nous cherchons à reconstituer le sens du vêtement, son origine par l'examen des représentations de certaines pièces exposées dans les musées égyptiens, et ce dans le but de faire revivre notre patrimoine copte pour en profiter dans le domaine touristique.

\section{Les vêtements liturgiques dans l'Ancien Testament}

Les vêtements liturgiques ne représentent pas une nouvelle tradition puisque déjà dans l'Ancien Testament Dieu a ordonné Moise à fabriquer des costumes spécifiques à son frère Aaron :" Tu feras pour ton frère Aaron les vêtements sacrés en signe de gloire et de majesté pour qu'il soit consacré et qu'il exerce mon sacerdoce.." (Ex 28:2-3). Les vêtements d'Aaron étaient plus compliqués que ceux des prêtres. Exode 28 et Lévitique (8:7-9) expliquent longuement les vêtements et leurs ornements: "Pectoral- éphod- robetunique brodée- turban- ceinture." (Pl. 1) La plupart des habits du grand- prêtre quand il officiait était en lin symbole de pureté. (Ez 44:17-18). ${ }^{4} \mathrm{Ces}$ habits rappellent ceux qui étaient revêtus par les anciens prêtres égyptiens et qui étaient faits en lin sans aucun autre fibre, symbole de pureté prace que les deux déesses Isis et Nephtys avaient filé, tissé et blanchi les vêtements de leur frère Osiris (faits en lin). ${ }^{5}$ 


\section{Les vêtements liturgiques dans le Nouveau Testament}

Le Nouveau Testament marque une rupture puisque aucun vêtement spécifique à l'action liturgique n'y est mentionné. Les vêtements portés par le clergé n'étaient pas définis. L'église orientale diffère de l'occidentale en ce qui concerne les costumes religieux, mais toutes les deux conservent leur symbolisme et se réfèrent aux vêtements du Christ. ${ }^{6}$

Or la 10ème loi établie par les Apôtres ordonne: "Les habits des prêtres diffèrent de ceux des laïques."7 Cette loi n'a pas été exécutée à cause de la persécution de l'église orientale qui n'était pas officiellement reconnue pendant ce temps-là. Saint Auriganius souligne que les prêtres ne portaient pas des habits spécifiques à Alexandrie.

Même après la période des persécutions, les prêtres ont continué à vêtir les habits laïcs quotidiens: St Augustin (354-430) célébrait la messe avec des habits ordinaires quotidiens. Puis, les Canons de Synode ont recommandé plus tard que les vêtements liturgiques soient simples, dépourvus de tout luxe. ${ }^{8}$ L'église copte recommande que les habits ecclésiastiques soient toujours blancs, signe de pureté et de lumière. En effet, les évangélistes dénotent "Ces vêtements deviennent blancs comme la lumière" (Mt 17:2) (Mc 9:3) ${ }^{9}$; et comme les Deux Anges qui paraissent après la Résurrection du Christ et lors de son Ascension (étaient en blanc ) (Ac 1:10). ${ }^{10}$ Saint Jean dans 1'Apocalypse décrit la foule innombrable devant le Seigneur par "vêtus de robes blanches" ( Ap 7:9) ${ }^{11}$. De même dans le livre des canons, livre de loi ( loi 96) on trouve ces propos: "Les habits portés par les prêtres dans les offices doivent être blancs comme ceux du Christ pendant la Transfiguration." Il était connu que les habits extérieurs portés par les moines étaient blancs. Cette couleur demeure jusqu'au règne d'Al-Hakim. ${ }^{12}$

L'église recommandait que ces habits soient toujours en lin, jamais en laine parce que Dieu a habillé Adam en laine après son péché et quand "il fut chassé du jardin d'Eden" (Gn 3:23). Le Lin ressemble aussi au linceul qui avait enveloppé le coprs du Christ dans la tombe (Lc 23:53). ${ }^{13}$ Mais ces habits pouvaient être brodés en soie avec des motifs de croix et de saints. ${ }^{14}$

\section{Les différentes sources mentionnant le nombre de vêtements ecclésiastiques selon les ordres}

Ibn El Moqaffa a affirmé au 11ème siècle que le costume ecclésiatique se composait de sept pièces:".. la tunique.. puis le tailsan.. et el zunnar pour ceindre la taille.. les deux manches qui délivrent les mains du prêtre pour qu'elles tiennent les sacrements, puis l'épitrichalion qui désigne pour lui “mille pierres", enfin el burnus pour les prêtres avec capuchon (qasla)..",15

Ibn El Assal au 13ème siècle, rapporte les paroles de Clément :"Le sticharion ne doit pas être fendu, l'orarion doit être arrondi et renforcé, le capuchon bonnet doit être large dans sa partie inférieure et brodé de trois surpiqûres. La tunique doit avoir des manches arrondies et surpiquées elles-aussi, en souvenir des liens de corde des pieds et des mains de Jésus. Un grand ômophorion à croix doit passer comme l'analabas dans la ceinture et sur les épaules ... pour représenter les liens qui furent mis autour du cou du Christ.",16

Les mêmes parties composent le costume ecclésiastique selon Ibn El Sebaâ au 13ème14ème siècle. ${ }^{17}$

Ibn Kabra explique comment procède le patriarche quand il consacre l'évêque : "Après plusieurs prières, il le revêt d'habits ecclésiatiques blancs.." 18 mais il n'indique pas clairement les pièces ecclésiastiques. 
Quant aux nouvelles références paraissant dans le manuscrit (9) à la bibliothèque patriarchale au Caire - n.227, qui datent du 19ème siècle (1568 copte- 1852 ap. J.C.), elles expliquent comment revêtir le patriarche des vêtements liturgiques : ".. On le revêt d'une robe courte pourpre.. puis l'épitrichalion ..puis la ceinture.. ensuite la manche droite.. deuxième manche.. puis on le revêt du tailsan .. et le burnus avec la qasla." 19

Nous allons essayer de décrire les pièces exposées dans les musées, leur importance et leur utilisation.( $\mathrm{Pl} .2)$

\section{Les vêtements Liturgiques}

Le sticharion (tunica) est porté par les trois degrés des ordres majeurs (diacres- prêtresévêques). ${ }^{20}$ Tunique (tunica) est un terme d'origine latine, qui signifie " démarche

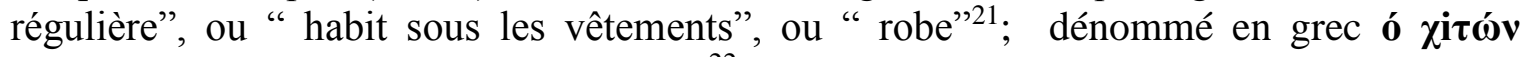
"sticharion" qui signifie le même sens. ${ }^{22}$ Et en copte "kolobione" c'est-à-dire est le symbole de la tunique du Christ : "Restait la tunique, elle était sans couture, tissée d'une seule pièce depuis le haut ... les soldats tirent au sort pour savoir à qui elle ira." (Mt 27:35) (Jn 19:23). ${ }^{23}$

Le sticharion est une longue tunique en lin blanc, large descendant jusqu'aux pieds, large aux épaules avec une enclure sur l'une des épaules, peut être boutonné , avec de larges manches brodées en fils dorés argentés selon les ordres. ${ }^{24}$

La décoration sur le sticharion est faite de motifs (croix) brodés sur les manches, la poitrine et le dos. ${ }^{25}$ Mais la décoration la plus ancienne et la plus simple semble être les "clavi", bandes verticales partant de l'épaule, mais parfois aussi appliquées sur les manches. ${ }^{26}$

Les auteurs donnent des inscriptions différentes de l'ornementation du sticharion. La tunique de l'évêque et du prêtre diffère de celle du diacre. Les manches de la première sont plus courtes parce que le prêtre porte sur ces manches d'autres manches extérieures. Elle était brodée en fil doré, argenté ou en soie. Le devant au niveau de la poitrine est décoré de représentations de la Sainte Vierge portant le Petit Jésus sur sa main gauche, entouré de croix et de quelques inscriptions. Dans la partie inférieure figure le personnage de Saint Georges transperçant le dragon ou les douze disciples, avec des anges ailés brodés sur les manches.

Les manches de la tunique du diacre étaient plus longues, brodées avec des fils argentés ou en soie, décorées avec des motifs de croix, des versets de la Bible ou le monogramme de Jésus. ${ }^{27}$

Actuellement les manches de la tunique du prêtre, ainsi que celles de l'évêque deviennent plus longues, plus larges, ils ne portent plus de manches extérieures. Elles sont uniquement brodées par les croix représentées sur les quatre côtés comme sorte de bénédiction, et les fils utilisés sont en coton et en soie et rarement dorées. ${ }^{28}$

Les musées en Egypte renferment plusieurs exemples de tuniques:

1- Tunique complète en lin blanc, au musée de tissage égyptien, brodée d'une seule couleur, par la forme d'un losange sur la poitrine, entourée de petites croix. A l'intérieur de la forme du losange, quatre carrés identiques contiennent chacun une croix copte. Cette unité est sur les manches. Troix croix ornent la partie centrale de la tunique. Un ruban brodé avec des motifs géométriques identiques entoure le cou. ${ }^{29}$ (Pl.3) 
2- Une tunique en lin. Elle date du 18ème siècle, préservée dans le musée national d'Alexandrie.

Cette tunique est brodée en lin blanc à col décolleté et de larges manches. Le décor est identique sur la face et le dos. Elle est en très bon état de conservation. Les manches sont brodées de deux larges lignes sur lesquelles sont marquées un motif de croix alterné à l'arrière et au devant sur un fond gris. On note également un fond de couleur jaune orné par de différentes croix de couleur rouge sur les deux côtés droit et gauche de la tunique. La face de la tunique au milieu est ornée de deux clavis (bandes verticales) décorées par de différentes formes de croix. La partie arrière de la tunique est surtout jaune également ornée de croix. ${ }^{30}(\mathrm{Pl} .4)$

3- Une des plus belles tuniques figure dans le musée copte, c'est celle d'un évêque en lin blanc cousu à la main en fil de soie. Cette aube est décorée avec la Vierge Marie portant dans la main gauche le Petit Jésus, trônant. Au -dessus de sa tête on voit deux anges portant un diadème pour le poser sur la tête de la Vierge et un triangle à l'intérieur duquel figure une colombe symbolisant "Le Saint- Esprit". Autour d'eux sur trois côtés, les bustes des douze disciples apparaissent dans un cadre brodé en vert, ils sont entourés de croix et de décorations géométriques et humaines. Sur les manches, on voit des portraits brodés de plusieurs saints dont Saint Mina et Saint Georges, de différents anges ainsi que des croix. ${ }^{31}$ Cette tunique date du 17 ème siècle ${ }^{.32}(\mathrm{Pl} .5)$

4- Cette tunique en lin blanc, dans le musée copte, comprend des rubans ornés de plantes et de cercles en laine et en lin ornés de motifs floraux et géométriques bruns. Vers l'extrémité des deux manches, on trouve deux bandes ornées de plantes et de formes géométriques. Elle date du 4ème ou du 6ème siècle. ${ }^{33}$ (Pl.6)

\section{Epitrichalion (pour les prêtres) ou étole - Orarion (pour les diacres) ou Zunnãr, appelé en arabe badrashil - Sidrah- bãlariyya}

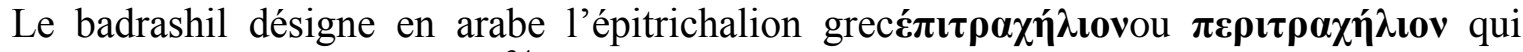
n'est que l'orarion romain. ${ }^{34} \mathrm{Le}$ mot badrashil signifie "ce qui est porté au cou". L'étymologie du terme "Orarion" est moins claire. Le mot serait peut être derivé du latin os "bouche" et ferait allusion à la fonction de l'orarion comme linge destiné à essuyer la bouche après la communion. ${ }^{35}$

Tous les ordres ecclésiastiques portent le badrashil mais il diffère dans la forme d'après l'ordre. Il est toujours porté sur la tunique. ${ }^{36}$ Il était spécifié comme un signe de la fonction diaconale. L'orarion en tant qu'ornement liturgique est cité dès le 4ème siècle au concile de Laodicée en $372 .{ }^{37}$ L'épitricharion des prêtres a été connu à l'occident avant d'être utilisé dans l'église orientale au 8ème siècle. ${ }^{38}$ Pour le diacre, l'orarion ou (Zunnar) est une longue étoffe en soie, en satin ou en coton, dont l'une des faces est rouge, symbole du sang du Christ, brodé de croix et les initiales de Jésus Christ (IC), l'autre face est bleue portée pendant les occasions graves comme la semaine de la Passion (Vendredi Saint) et dans les funérailles. ${ }^{39} \mathrm{~L}$ 'orarion passe sur l'épaule gauche puis sur le dos sous le bras droit et remonte sur l'épaule droite, l'une des extrémités pend sur le dos et l'autre sur la poitrine. Pour les sous-diacres le milieu de l'orarion est posé par devant, à la hauteur de la taille, les deux parties (droite et gauche) de l'orarion se croisent ensuite sur le dos, puis passent sur les épaules, elles retombent enfin verticalement par-devant, les deux extrémités arrivent au-desous de la taille, de sorte que l'orarion forme un (X) dans le dos et un $(\mathrm{H})$ par devant. ${ }^{40}(\mathrm{Pl} .7)$ 
L'épitrichalion du prêtre nommée "Sadriah" est une longue bande qui couvre la poitrine et dont une petite partie descend sur le dos, avec une enclure au milieu pour la tête. Il est fait en soie, coton, velours, ou satin. Il est de couleur rouge ou cramoisi, bleu ou crème. C'est l'ornementation qui fait la différence entre l'épitrichalion du prêtre et celui de l'évêque et du patriarche. La "sadriah" du prêtre n'est ornée qu'avec des croix en fil doré ou argenté. Celle du patriarche est ornée par la représentation des douze disciples représentés deux par deux et au-dessus de chacun d'eux son nom inscrit en langue arabe avec des versets de la Bible, parfois le nom de l'église "le wakf", et la date de la fabrication de l'étole, et le nom de la personne qui a contribué à la fabrication de cet épitrichalion. ${ }^{41}$

St Isithorius indique que certains portraits découverts représentent des patriarches portant l'épitrichalion non sous forme de "sadriah" mais sous forme de longue bande appelée "omopharion" 42 . On peut même rappeler que la badrashil était utilisé par Aaron le prêtre dans l'Ancien Testament. ${ }^{43}$

Exemples représentant les épitrichalions dans les musées:

1- Un épitrichalion porté par les évêques durant les céremonies, fabriqué en soie et qui date du 18ème siècle. Cette étole de couleur crème, est brodée autour du cou, par des inscriptions tissées en arabe. En dessous de l'enclure, les douze disciples sont représentés en deux rangs entourés de brodures. Le nom de chacun d'entre eux est inscrit en arabe au-dessus de sa tête. La partie inférieure du vêtement est ornée de franges. Cet épitrichalion est preservé dans le musée des Antiquités de la bibliothèque d'Alexandrie. $^{44}(\mathrm{Pl} .8)$

2- Epitrichalion en velours rouge exposé au musée national d'Alexandrie, qui était un wakf pour la Cathédrale de Saint Marc à Alexandrie. Il date du 18ème-19ème siècle. C'est une étoffe rectangulaire avec une enclure, ornée en fil doré et argenté. Au -dessous de l'enclure, on trouve une inscription en arabe:

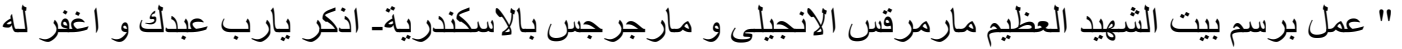

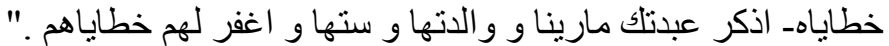

Les douze disciples sont représentés et le nom de chacun est inscrit au-dessus de sa tête . Cette pièce était preservée dans le musée copte. ${ }^{45}$ (Pl.9)

3- Epitrichalion en soie rouge décoré en fil argenté, wakf à l'église de la Résurrection à Jérusalem. Il s'agit d'une bande rectangulaire dotée d'une ouverture au sommet via laquelle le prêtre passe la tête avec cette inscription en langue arabe:

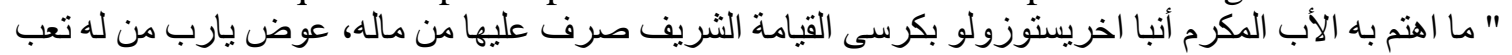

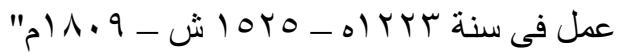

Puis des représentations des douze disciples, leurs noms et des motifs décoratifs en fil d'argent sont brodés sur l'étole. Les douze disciples sont représentés avec des nimbes brodées avec des fils en soie. Ils sont barbus et leurs noms sont classés en arabe dans l'ordre suivant :

À droite: Simon appelé Pierre, Jacques le fils de Zébédée, Philippe, Thomas, Jacques le fils d'Alphée et Simon le cananéen.

À gauche: André le frère de Pierre, Jean, Barthélémy, Matthieu le publicain, Thadée et Mathias.

Cet épitrichalion est preservé dans le deuxième étage du musée copte ${ }^{46}(\mathrm{Pl} .10)$

Cette étole en soie, préservée dans le musée copte, est brodée d'images des douze disciples, leurs noms sont inscrits en arabe et des motifs décoratifs en fil d'argent. Ils sont 
classés dans le même ordre de l'exemple précédent. Elle se compose de deux sections réunies au milieu par le même type de broderie. Elle représente du haut deux croix coptes puis des inscriptions en arabe, dont on peut lire aussi sur les manches:

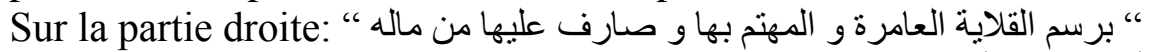

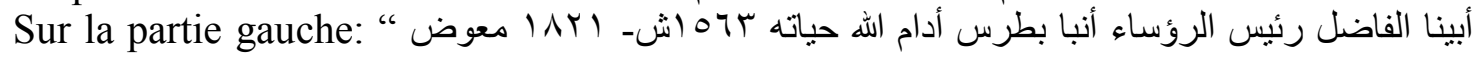
“بارب ${ }^{47}(\mathrm{Pl} .11)$

\section{La Zone (la ceinture) (Zonarion ou Zunnãr), dit en arabe (hiyãsah- mintaqah)}

La zone ou la ceinture est dénommée "hiyãsah" dans l'église ${ }^{48}$. C'est un terme

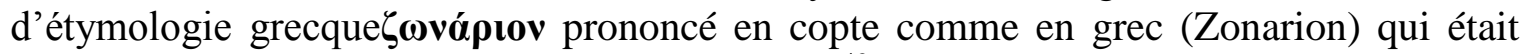
prononcé aussi bien en grec qu' en copte (orarion) ${ }^{49}$.

Le terme "mintaqah" "se préparer" puisque l'évêque se prépare pour l'office. ${ }^{50}$

Il s'agit d'une large ceinture en laine ou en soie embellie de fils dorés et de croix, dont les extrémités sont reliées au devant par une ceinture en argent.( Pl.12) Elle était utilisée par le patriarche, l'évêque et le prêtre mais actuellement le patriarche et l'évêque sont les seuls à l'utiliser. Elle est portée par-dessus le sticharion et l'épitrichalion . ${ }^{51}$

Les coptes ont utilisé le mintaqah depuis le 4ème siècle et l'occident depuis le 8ème siècle. Elle rappelle la ceinture utilisée par Aaron le prêtre dans la tenue du travail" (Ex $28)^{52}$ et devient comme signe de vigilance et de préparation comme le fait le Christ (Lc 12:35 $)^{53 ،}$ Jésus se lève de table, prend un linge dont il se ceint."

Certains pensent que le Zinnar fait allusion au fouet qui a flagellé le Christ ou aux cordes qui ligotent le Christ pour l'emmener de la résidence de Hanne à Caïphe puis à Ponce Pilate. (Jn 18:13 - Jn 19:1). ${ }^{54}$

Elle fait également allusion à l'Apocalypse de Jean évoquant le Christ: "Il était vêtu d'une longue robe, une ceinture d'or lui serrait la poitrine." (Ap 1:13). ${ }^{55}$

Mais le zunnãr utilisé dans l'office à l'intérieur de l'église est différent de celui du moine qui est fabriqué en cuir avec des motifs de croix, celui -ci l'utilise pendant la prière, ${ }^{56}$ et diffère également du zunnãr (ruban) que le prêtre noue sur l'épaule du baptisé comme union au Christ ou qu'il noue sur l'épaule du marié symbole de son union avec la mariée. ${ }^{57}$

\section{Les manches indépendantes-Epimanikia (en arabe: Kummãn- akmam)}

Elles sont dénommées (epimanikia) en grec et (kamission) en copte. Elles faisaient partie des habits ecclésiastiques portés par le patriarche, l'évêque et sont rarement utilisées actuellement. ${ }^{58}$

Elles étaient faites pour retenir les manches assez larges du sticharion et éviter que celles-ci n'effleurent les offrandes eucharistiques. ${ }^{59}$

Elles étaient faites des mêmes matières que l'épitrichalion, c'est-à-dire en soie ou en velours. ${ }^{60}$

Les manches étaient ornées de croix ou du monogramme du Christ ou des motifs végétaux et des représentations des saints et des anges, des versets des Psaumes étaient inscrits: sur la manche droite :"... La droite du Seigneur fait un exploit! La droite du Seigneur est levée ! la droite du Seigneur fait un exploit!" (Ps 118:15-16)

Sur la manche gauche: "Tes mains m'ont fait et affermi, rends-moi intelligent et j'étudierai tes commandements." (Ps 119:73) ${ }^{61}$ 
L'utilisation des manches indépendantes remonte au temps des Apôtres. D'après les églises grecque et copte, l'utilisation des manches est symbolique. Elles font allusion aux cordes qui ont ligoté le corps du Christ quand il fut flagellé.

Les Syriens en donnent une autre interprétation, ils pensent que les manches étaient des mouchoirs que les prêtres utilisaient pour essuyer leurs larmes. Cette hypothèse a été rejetée par l'église copte. ${ }^{62}$

Ce sont les moines égyptiens qui transférèrent l'habitude du port de ces manches aux pays de Gaule (France) dans les premières ères chrétiennes. Elles paraissent clairement à l'occident au 6ème siècle. ${ }^{63}$

Nous avons deux exemples de manches:

1- Deux manches au musée copte, en soie rouge brodées en fil argenté, la manche droite contient des croix et la représentation de la Sainte Vierge portant le Petit Jésus. Sur l'un des poignets le verset cité auparavant (Ps 118:15-16). Un saint entouré de croix est représenté sur la manche gauche. Il tient une baguette sur laquelle est inscrit : "Vos mains m'ont crée et m'ont crucifié - expliquez-moi révérend père patriarche Pierre, que Dieu le garde 1821 ap. J.C, 1563 des martyrs. Récompense le Seigneur." Ces manches datent du 19ème siècle. ${ }^{64}(\mathrm{Pl} .13)$

2- Deux manches ont été découvertes dans l'église des Saints Cyr et Jean au vieux Caire faites en velours cramoisi, brodées avec des étoiles, des croix en fil épais argenté. L'une des manches est décorée par la représentation de la Vierge et du Petit Jésus. Leurs têtes sont couronnées et nimbées. Sur l'autre manche figure un ange ailé. ${ }^{65}$ Cette inscription en arabe est inscrite sur les deux manches:

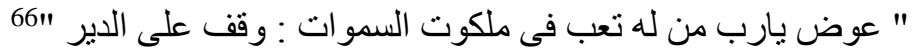

La beauté de ces manches indique qu'elles avaient appartenu à un évêque sans doute de celui de Babylone et date peut-être du 16ème siècle. Elles sont actuellement au musée de tissage au Caire. ${ }^{67}$ (Pl.14)

\section{Le Ballin ou l'Omophorion (Epomis ou Amice) dénommé en arabe ( tailsãn- Shamlah)}

Les patriarches et les évêques portaient le ballin en des occasions spéciales (Vendredi Saint), mais jamais pendant la messe. Ce ballin a été transformé en shamlah ou tailsãn.

Le ballin est synonyme de l'omophorion, derivé du grec et qui signifie "suspendu sur l'épaule", dénommé en "Pi- ballin" qui signifie "le ballin blanc". 68

L'omophorion est une pièce par laquelle l'évêque couvre la tête. De la tête pendent devant la poitrine deux parties du ballin (la partie droite et la partie gauche) pliées en deux dans le sens de la longueur; la partie droite et la partie gauche sont croisées, sur la poitrine, elles passent sous les bras et sont croisées dans le dos, passent sur les épaules et pendent par-devant au-dessus de la ceinture (zunnãr). Il était fait de soie ou de laine, blanc ou rouge, brodé en fil doré, embelli de pierres précieuses.( Pl.15) Il symbolise la couronne d'épines et les bandelettes avec lesquelles Nicodème et Joseph d'Arimathée entourèrent le corps du Christ pour l'ensevelir (Jn19:40). ${ }^{69}$ L'omophorion était porté presque comme le châle que portaient les moines pachomiens. ${ }^{70}$

Il est à noter que le ballin n'a pas été mentionné dans les rites coptes concernant la consécration des archevêques et des évêques, mais uniquement pour les patriarches. ${ }^{71}$ Le shamla est une étoffe rectangulaire portée au-dessous du burnus faite en soie ou en lin blanc brodé avec deux croix, l'une sur la tête, l'autre sur le dos. ${ }^{72}$ (Pl.16) 
Sa forme a changé, elle ressemble à une couronne qu'on dénomme "tailsana- epomis", similaire au casque porté par les soldats, utilisé seulement par les prêtres orientaux. ${ }^{73}$

La plupart des chercheurs pensent que le ballin ou le shamla avaient débuté dans les églises orientales puis ils ont été transférés dans les églises occidentales. Il était utilisé surtout pour protéger le cou de la chaleur du climat. ${ }^{74}$

Le shamla est devenu plus court, la plupart du temps est orné d'une seule croix au milieu au-dessus de la tête, porté par le prêtre parce que le patriarche porte plutôt une couronne , sinon il la met au-dessus de la qolonusua. ${ }^{75}$

On possède un seul exemple d'omophorion d'un patriarche ou d'un évêque, dénommé dans certaines références épitrichalion, exposé dans le musée de tissage au Caire. Ce ballin est une sorte de longue bande utilisée plutôt dans l'église d'Alexandrie, fabriqué en soie. Il est d'origine grecque. Des saints sont représentés brodés minutieusement. Le nom de chaque saint est inscrit au-dessus de sa tête en langue grecque en lettres abrégées: ".. Saint Georges, Saint Nicolas.." et ces saints sont representés portant les habits ecclésiastiques chacun à l'intérieur d'une niche en forme d'un arche trilobé soutenu par deux colonnes. Une bande ornée de motifs floraux et végétaux sépare entre eux. Ce ballin qui date du 16ème siècle est embelli de pierres préciseuses et appartenait au musée copte. $^{76}(\mathrm{Pl} .17)$

\section{Le Phelonion ou le Burnus (en arabe faluniyum- burnus)}

Le burnus est dénommé phelonion ou koklonion ou omophorion, d'étymologie grecque. A l'origine il était l'habit des prophètes et des rois. C'est le vêtement porté au-dessus du sticharion et de l'épitrichalion surtout pendant les cérémonies et qui rappelle les habits d'Aaron le prêtre. Le burnus ressemble plutôt à un manteau, ouvert de devant sans manches, fait en soie ou en laine (La même matière de l'épitrichalion) brodé en formes de croix et d'inscriptions religieuses.( Pl.18) Il rappelle le manteau de pourpre que le roi Hérode habille au Christ au moment de la crucifixion (Mt 15:17) (Lc 23:11). ${ }^{77}$

Le burnus avec le capuchon (qasla- koulla) semble avoir été réservé aux évêques et aux patriarches et constitue une marque distinctive. ${ }^{78}$ Cette forme de burnus était connue dès la période du pape CyrilI( Amoud El Din) (عمود الدين ) (412-444), d'après le décret du concile d'Ephèse (431). ${ }^{79}$ Le musée copte renfermait dans le passé plusieurs burnus.

\section{Le Mitre (dit en arabe tâj)}

Le "tâj" est dénommé "Mitra" en grec ${ }^{80}$. Il est porté par le patriarche et les évêques uniquement pendant l'office. Il est ôté pendant la lecture de l'évangile. Il est fait en soie et est orné en or ou en argent arrondi comme la coupe dans sa partie inférieure. Le Christ, la Sainte Vierge, les quatre évangelistes y sont représentés et une croix le surmonte ${ }^{81}$.

Le pape Cyril I ( 404-434) était le premier pape à porter le mitre dans l'église d'Alexandrie suivant un des décrets du concile d'Ephèse en 431 ap. J.C ${ }^{82}$, cela contredit ce qu'avait déclaré Athanasius El Makary que le tãj a été connu dans l'église orientale après la chute de Constantinople en $1453 .{ }^{83}$ Le mitre ne fait pas partie des habits ecclésiastiques mais il devient un insigne liturgique.

Rappelons les paroles de Butler qui avait annoncé clairement que le mitre est le symbole du pouvoir porté par le patriarche d'Alexandrie lors de sa concécration. ${ }^{84}$

Le mitre est le symbole de la couronne d'épines posée sur la tête du Christ. (Jn 19:5) ainsi qu'aux bandelettes posées sur son tombeau. (Jn 20:7). ${ }^{85}$ 
Le musée copte renferme deux couronnes patriarchales:

1- Mitre éthiopien unique fabriqué en bronze enrichi d'or et de pierres précieuses avec une croix à l'intérieur d'un cerle et entouré de sept petites croix. Ce mitre a été envoyé par l'empereur "Menlik II" de l'Ethiopie au pape Cyril V (le 112ème patriarche d'Alexandrie) (1874-1927). Il a été offert au musée copte par son successeur le pape Youhanes. Il porte cette inscription en Amharic: " Couronne de Negus, Jean le roi de l'Ethiopie". Il est incrusté de representations de la Sainte Vierge, de Jésus- Christ ainsi que des saints. ${ }^{86}$ Butler en a fait l'éloge dans son livre en le décrivant ${ }^{87}$.( Pl.19)

2- Un mitre d'évêque qui date du 12ème-13ème siècle fabriqué en bronze enrichi d'argent avec une doublure de velours cramoisi. Il est composé de huit bandes en métal orné de motifs géométriques et surmonté d'une dôme avec une croix. ${ }^{88} \mathrm{Il}$ a été découvert à l'église d'Abu Seifein au vieux Caire. ${ }^{89}$ (P1. 20)

\section{Le Bâton pastoral (cukkâz en arabe)}

Le bâton est essentiel au patriarche et à l'évêque.

Ibn El Sebae a mentionné: "après que l'évêque revêt le patriarche du costume liturgique complet, celui -ci reçoit son bâton du-dessus de l'autel avec la croix. "90 Et Ibn El Moqaffae avait affirmé les mêmes paroles. ${ }^{91}$

Ce bâton est fabriqué en bois d'ébène, enrichi en argent. Quant à la tête, elle ressemble à deux serpents, faits en or ou en argent, l'un opposé à l'autre, au milieu desquels se situe une croix. ${ }^{92}$

Ce bâton est dénommé en grec "Rafoudos" et en copte "Bi- echfout" " 93 " بى اشفوت Le bâton semble avoir été considéré déjà par les Apôtres comme signe de pouvoir. ${ }^{94}$ Le bâton symbolise le bâton de Moise transformé en serpent, ainsi que le coup de lance qui frappe le côté du Christ (Jn 19:24) et l'éponge imbibée de vinaigre au bout d'une branche d'hysope. (Jn 19: 29) ${ }^{95}$

On possède un exemple de bâton pastoral dans le musée copte fabriqué en ivoire blanc orné de motifs géométriques en or, qui date du 19ème siècle. Ce bâton est de fabrication ethiopienne. Il est décoré de part et d'autre de formes géométriques peintes en relief avec des motifs en or. Son extrémité est arrondie et également ornée de formes géométriques en relief. Quant à la tête, elle ressemble à un serpent. La partie supérieure de ce bâton est décoré de motifs végétaux en or. Le dos présente des formes géométriques et des plantes en relief non décorées. Des incisions sont visibles au milieu. En-dessous, tant sur la face avant qu'arrière, on peut voir des formes géométriques en or au milieu desquelles se trouvent deux pièces rouges. La partie inférieure tant sur la face avant qu'arrière présente un relief circulaire composé de fleurs et surmonté de petites pierres rouges. ${ }^{96}(\mathrm{Pl} .21)$

\section{Les Chaussons (en arabe taliga)}

Les chaussons ne faisaient pas partie des habits ecclésiastiques. Comme le fait noter Ibn El Assal, d'après les paroles de Saint Basilios dans sa loi 96:" Personne ne rentre à l'autel portant des chaussures." Selon l'ordre de Dieu à Moise :" Retire tes sandales de tes pieds car le lieu où tu te tiens est une Terre Sainte" (Ex 3:5)97. D'ailleurs, jusqu'au début du 19ème siècle, les coptes rentraient à l'église pieds nus, cette habitude demeure jusqu'à nos jours dans les monastéres et dans les églises de la haute Egypte. "El taliga" est une espèce de chaussons en coton ou en laine portés par tous les orders du patriarche aux diacre.98 


\section{La croix pectorale}

Le clergé copte tient une croix à la main droite (symbole de la croix du Christ), il l'utilise pour donner la bénédiction ${ }^{99}$.

\section{Conclusion}

Nous pouvons conclure en soulignant que les vêtements et les insignes liturgiques ont une importance particulière. Ils sont considérés comme des éléments de performativité du rite. Les vêtements d'Aaron le prêtre constituent l'origine de ces vêtements. Ils ont subi des transformations.

Les différentes sources et réferences que nous avons citées nous ont longuement renseignés sur ces habits ecclésiatiques qui étaient fabriqués la plupart du temps en lin blanc.

D'ailleurs, les exemples exposés dans les musées nous informent sur les insignes et les vêtements liturgiques qui sont: la tunique (le sticharion), l'épitrichalion (l'orarion pour le diacre), la zone (Zunnar), les manches (epimanika), l'omophorion ou le ballin, le burnus, le mitre, le bâton, les chaussons et la croix pectoral qui représentent un patrimoine copte unique que nous devons préserver.

C'est pourquoi nous aspirons à la construction d'un musée spécial qui regrouperait les pièces éparpillées dans différentes salles des musées d'Egypte. Nous pourrions ajouter quelques salles dans le musée de tissage au Caire ou dans le musée copte ou bien intégrer un musée dans la cathédrale de Saint Marc à Abbaseya pour regrouper ces pièces ainsi que d'autres pièces.

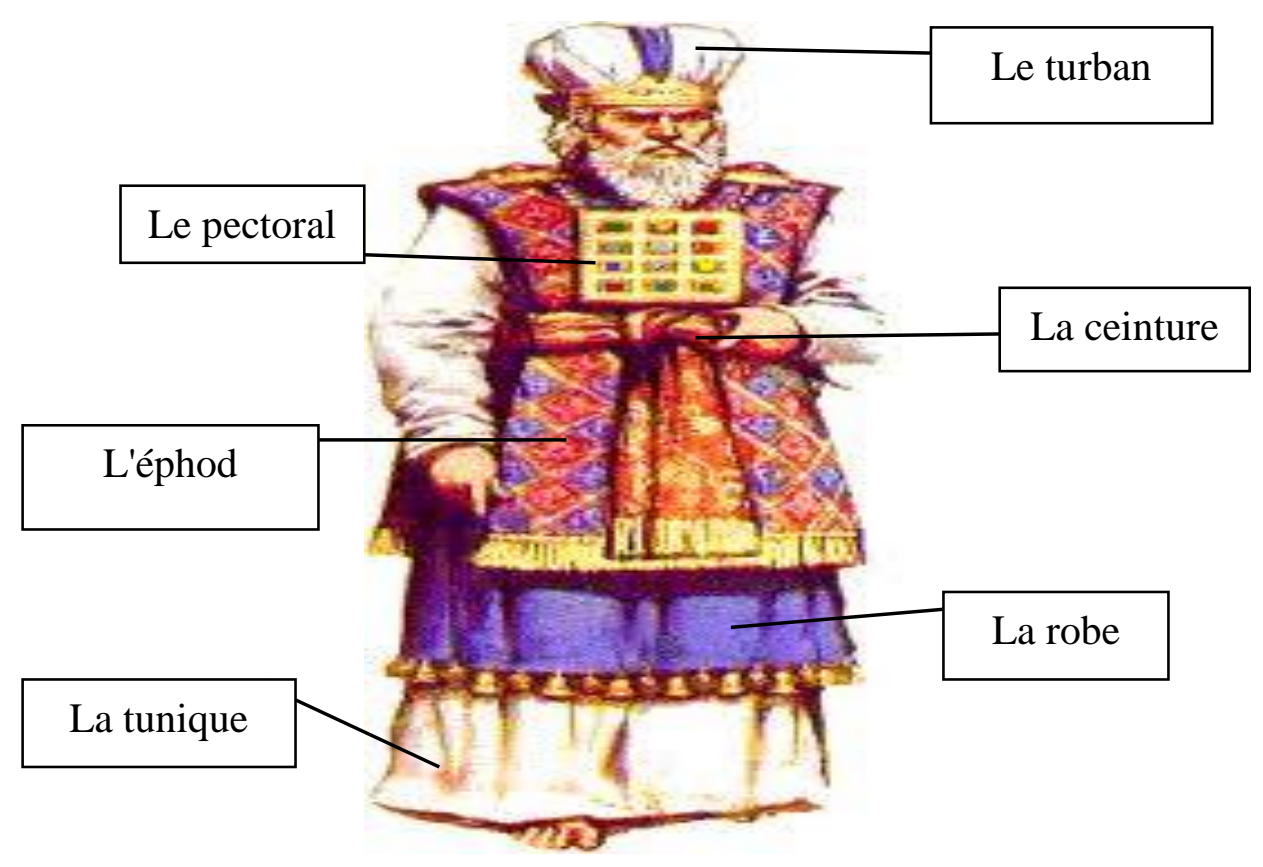

P1. 1: La représentation des vêtements d'Aaron 


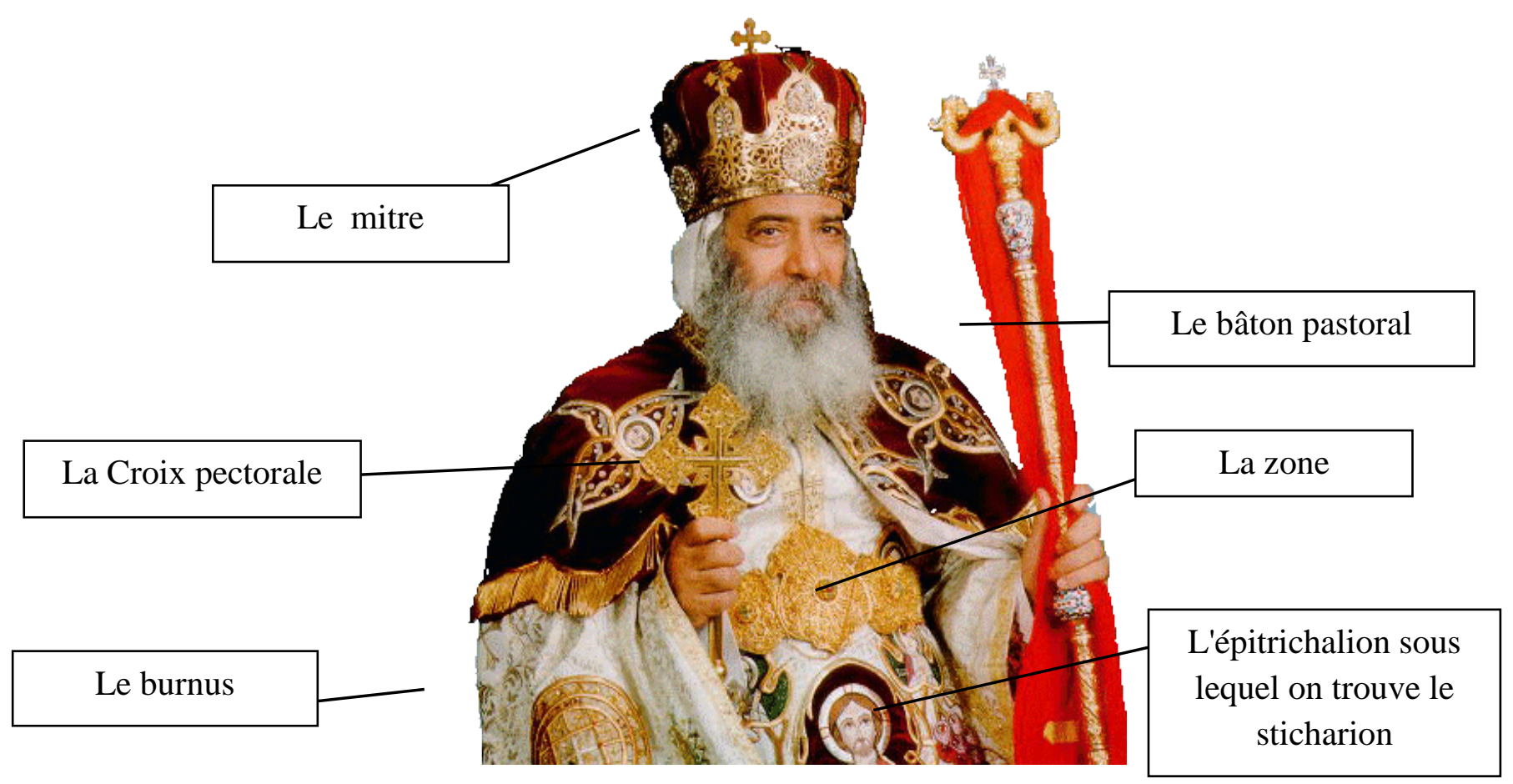

Pl. 2: La représentation des vêtements liturgiques

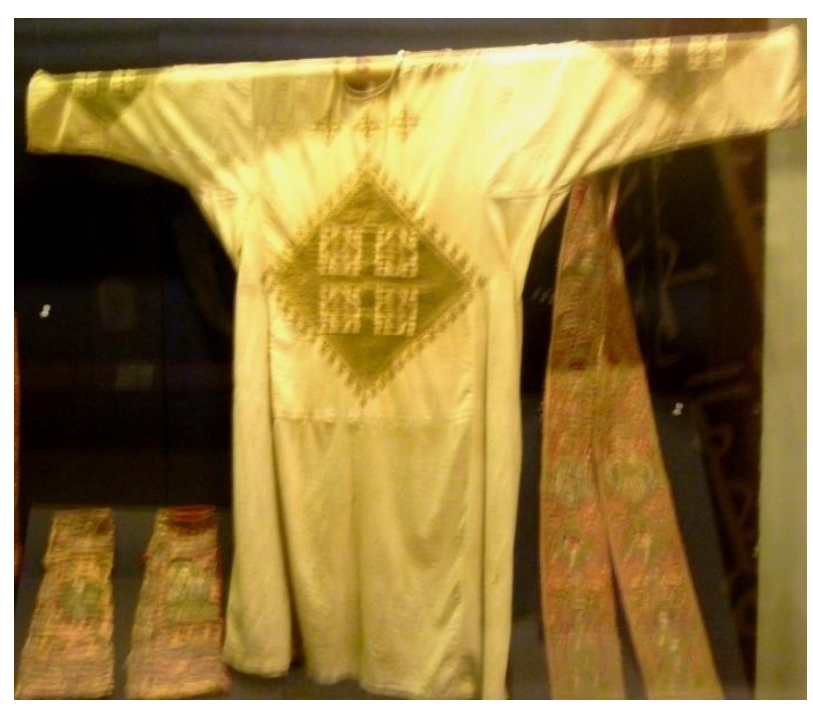

Pl .3: Tunique complète en lin blanc, exposée dans le musée de tissage égyptien 

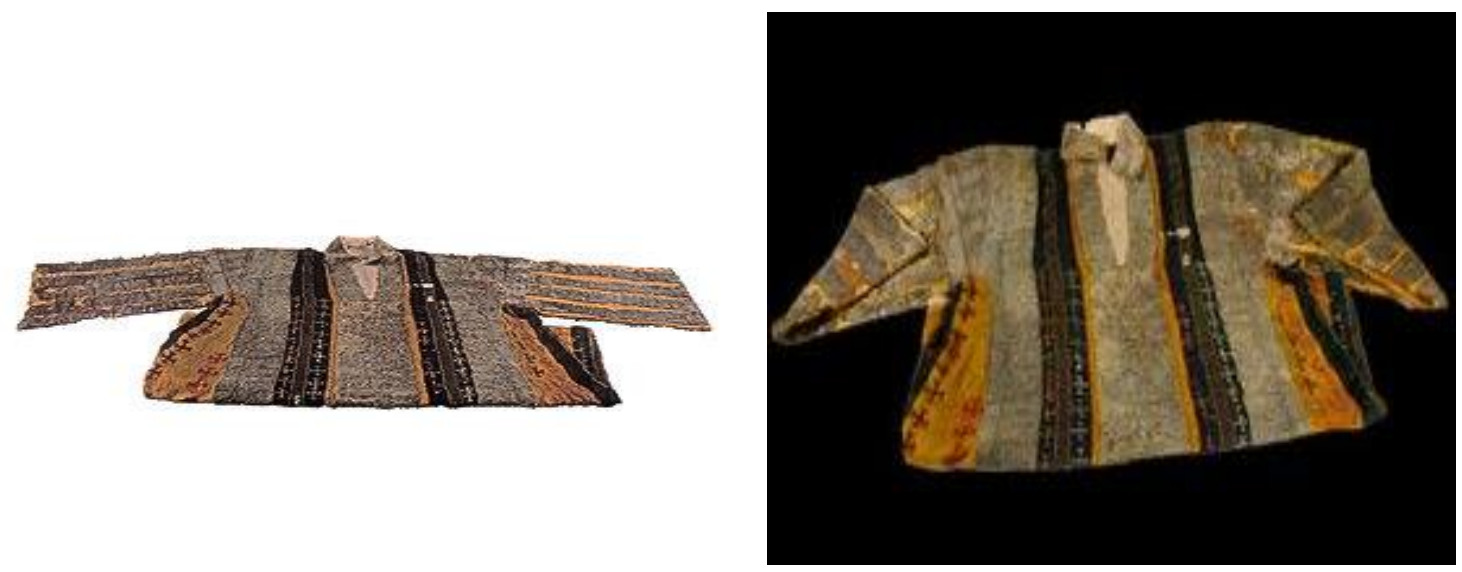

Pl. 4: Tunique en lin, exposée dans le musée nationald'Alexandrie. (www.alexmuseum.gov.eg)

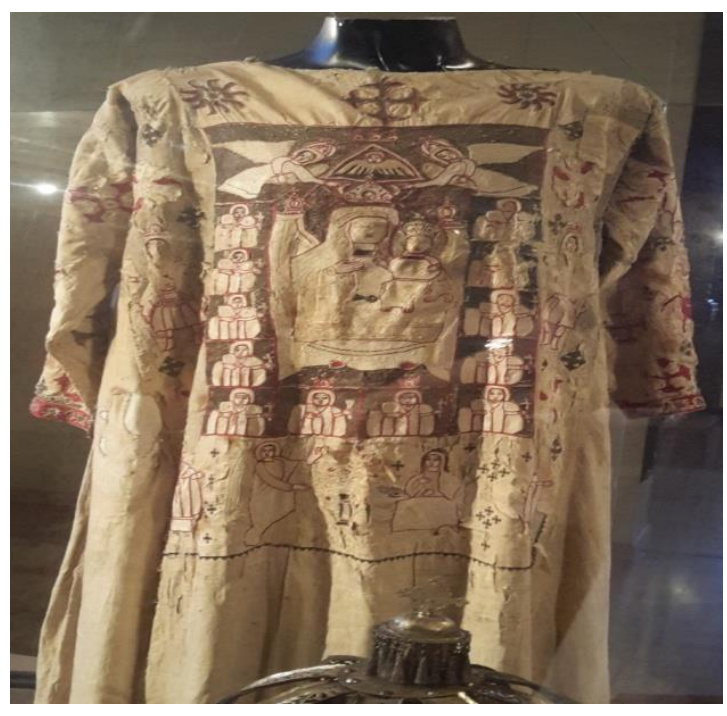

Pl. 5: La tunique d'un patriarche ou d'un évéque, dans le musée copte. 

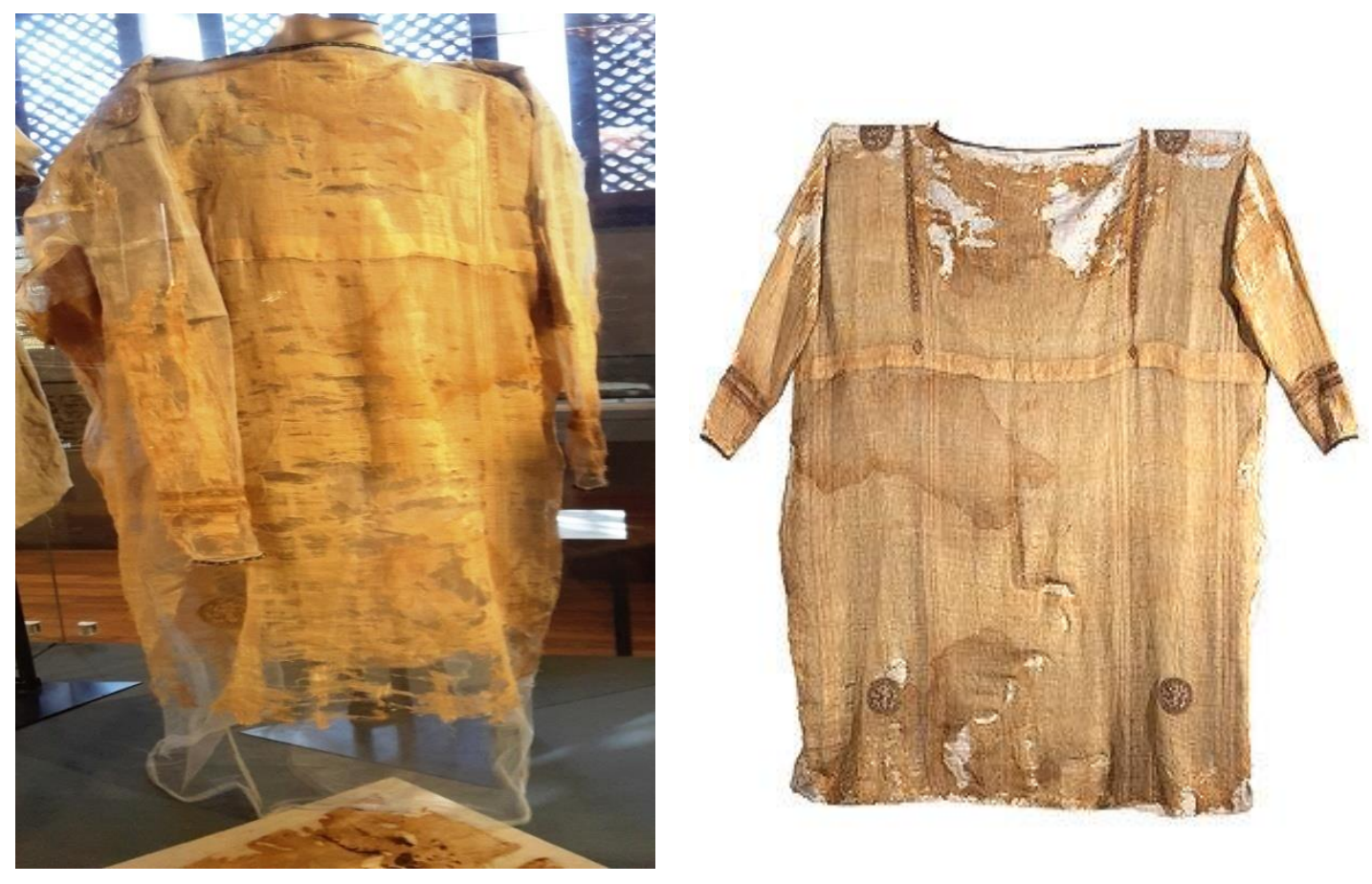

Pl. 6: Un sticharion simple en lin blanc, dans le musée copte
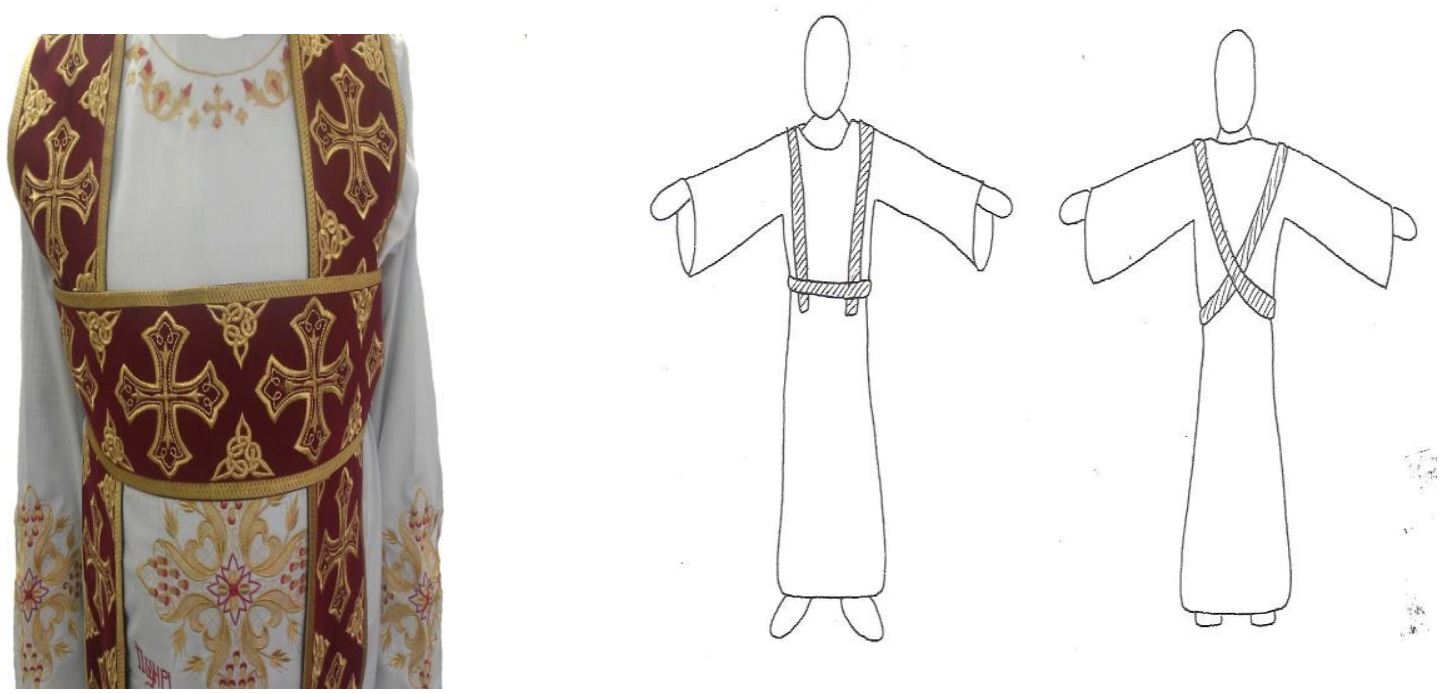

Pl. 7: La forme de l'orarion des diacres. ( de: Karel C. Innemée , "Ecclesiastical Dress in the Medieval Near East," E.J.Brill ( Leiden- New York, 1992), 47) . 

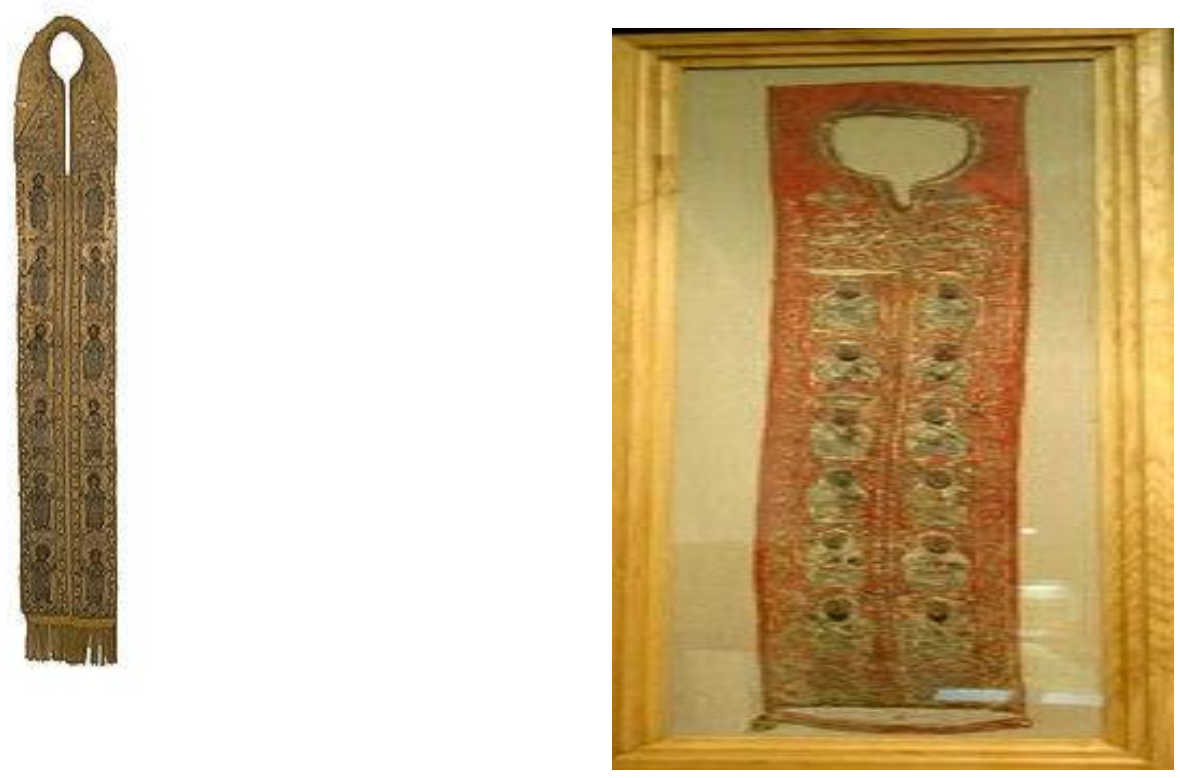

A

B

Pl.8: ( A) L'épitrichalion en couleur crème, préservé dans le musée des Antiquités de la Bibliothèque d'Alexandrie. (http://antiquites.bibalex.org)

Pl. 9: ( B) L'épitrichalion en velours rouge exposé dans le musée nationald'Alexandrie.

(www.alexmuseum.gov.eg)
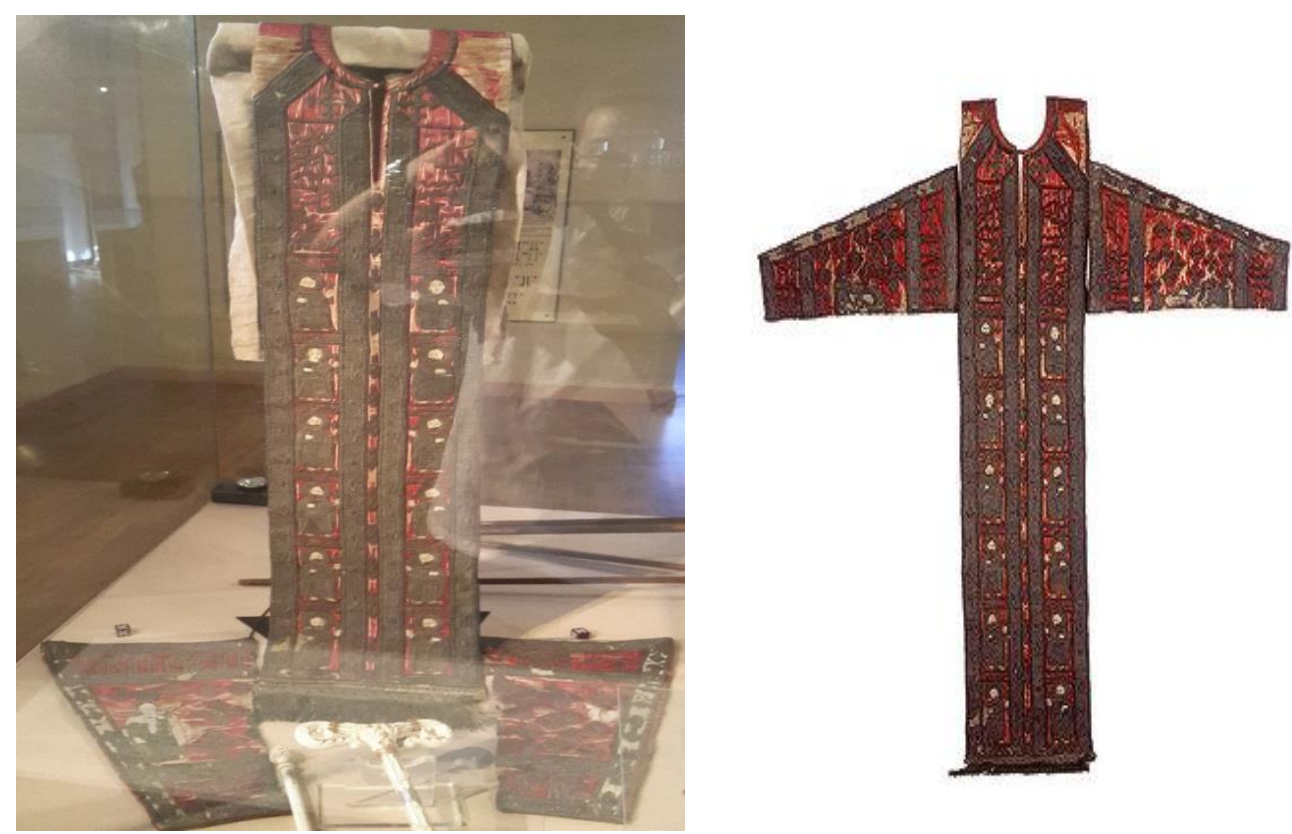

Pl. 10: L'épitrichalion en soie rouge exposé dans le musée copte. ( Visite sur le champ, www.eternalegypt.org) 

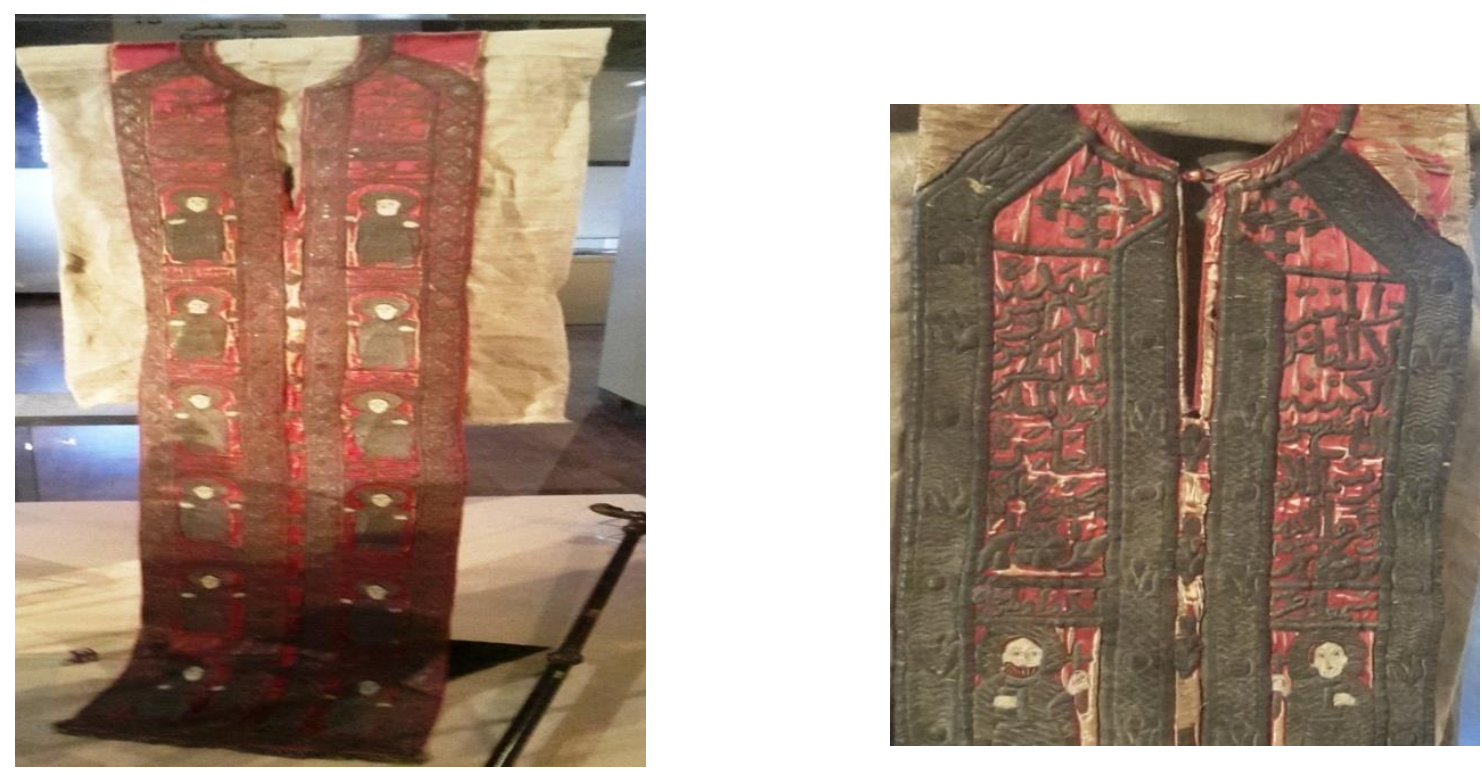

Pl. 11: L'épitrichalion en soie rouge exposé dans le musée copte.

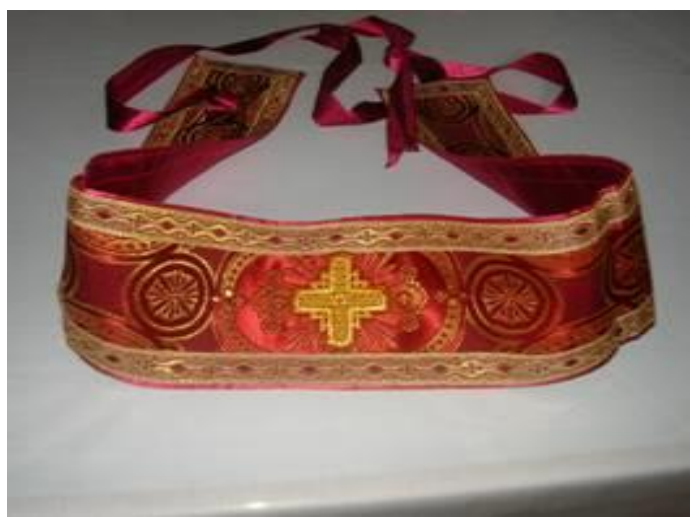

Pl. 12: La forme d'un Zonarion 


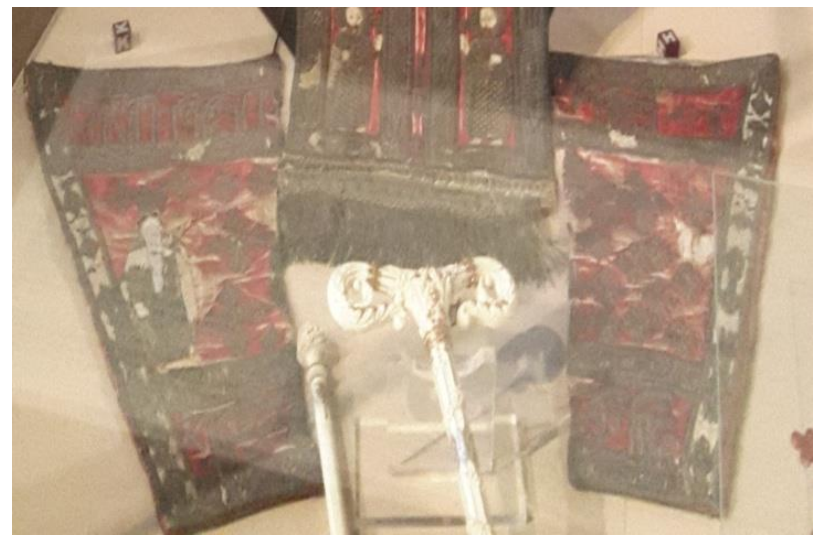

A

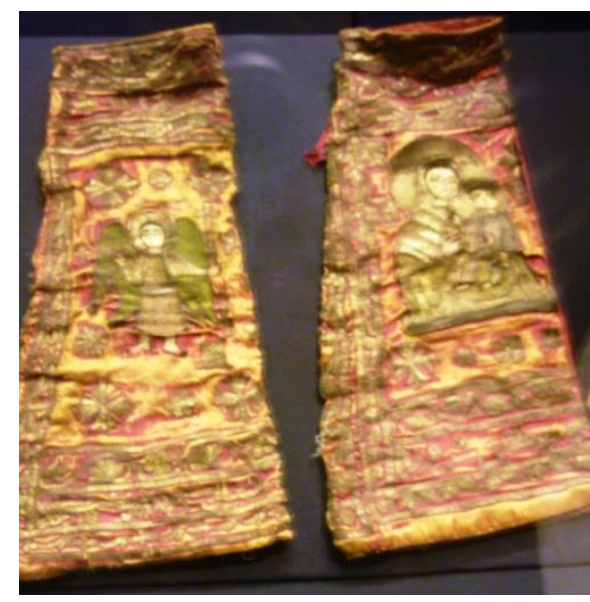

B

P1.13: ( A) Deux manches au musée copte en soie rouge.

Pl. 14: (B) Deux manches découvertes dans l'église de SS. Cyr et Jean au Vieux-Caire, exposées dans le musée de tissage égyptien.
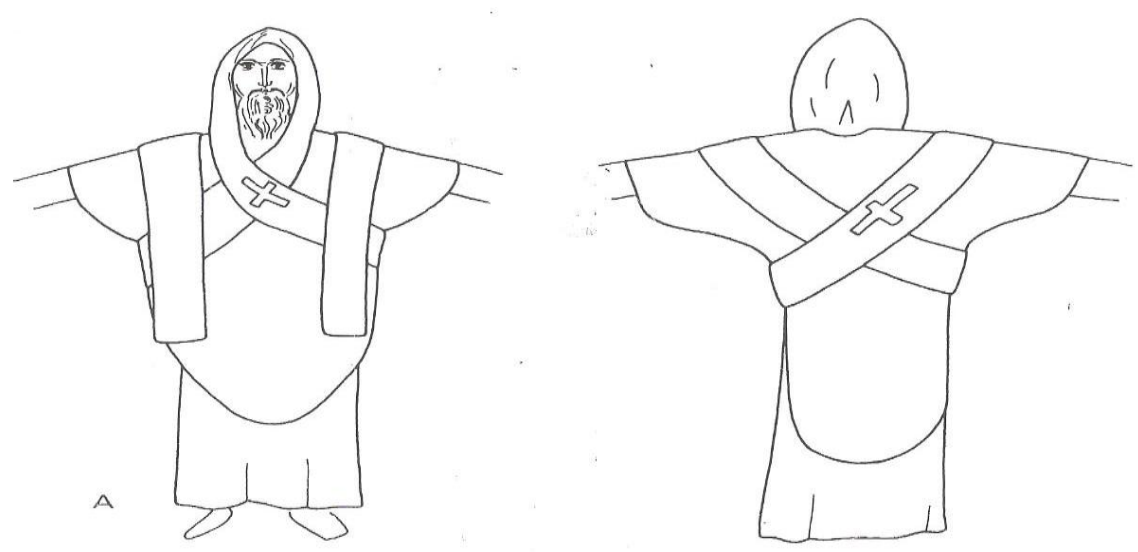

Pl. 15: La forme de ballin ou de l'omophorion (de: Paul Van Moorsel, " Les peintures du monastère de Saint Antoine," Vol.1, IFAO (Le Caire, 1992),54. ) 

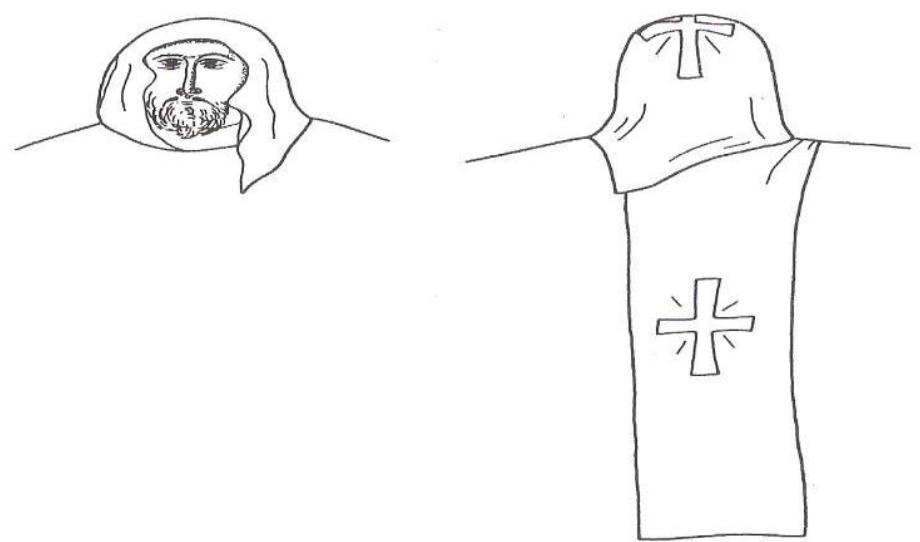

Pl. 16: L'épomis ou la shamla (de:Moorsel, " Les peintures du monastère de Saint Antoine," 51)
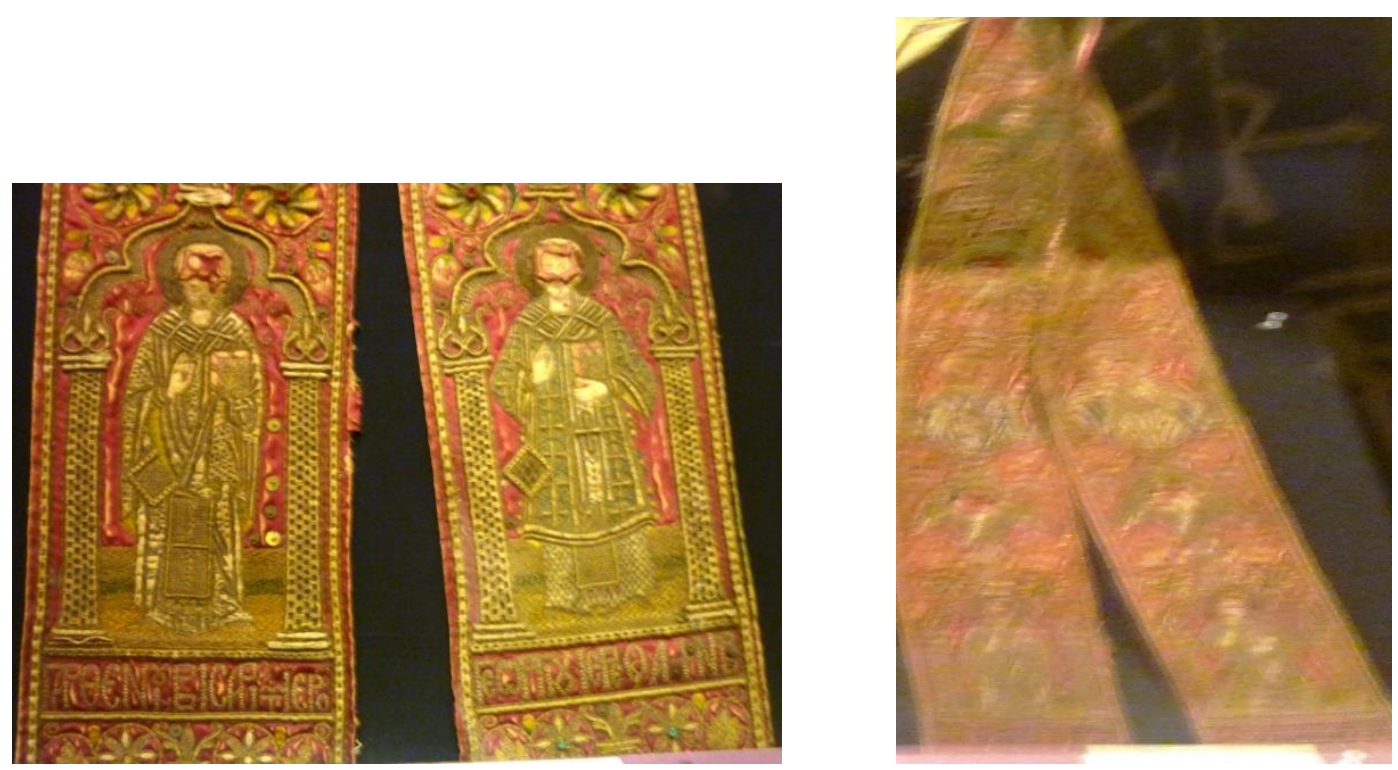

Pl. 17: L'omophorion d'un patriarche d'origine grecque, exposé dans le musée de tissage egyptien.

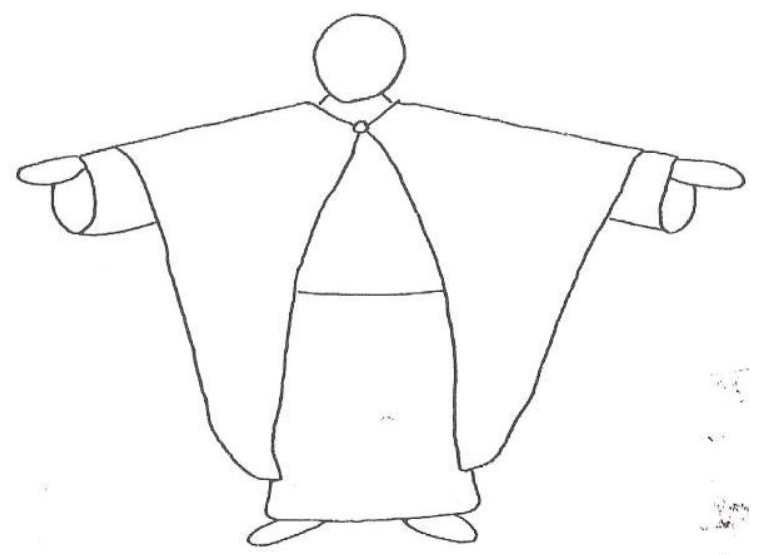

Pl. 18: Le burnus ou le phelonion copte (de: Innemée , " Ecclesiastical Dress," 50) 


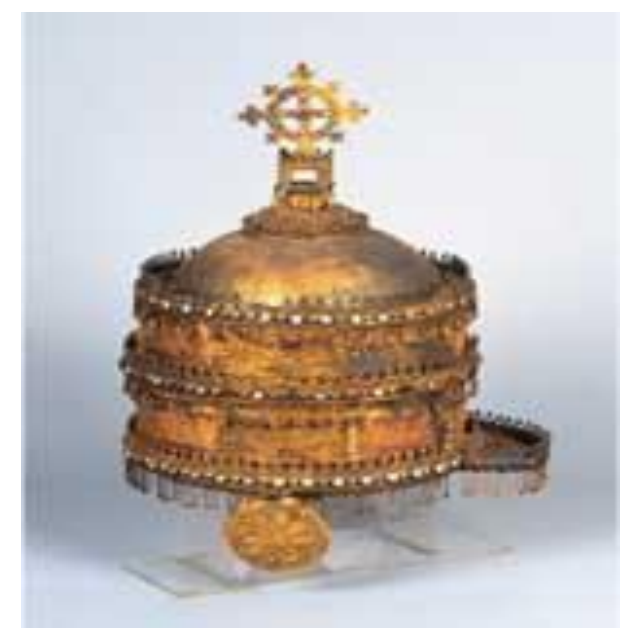

A

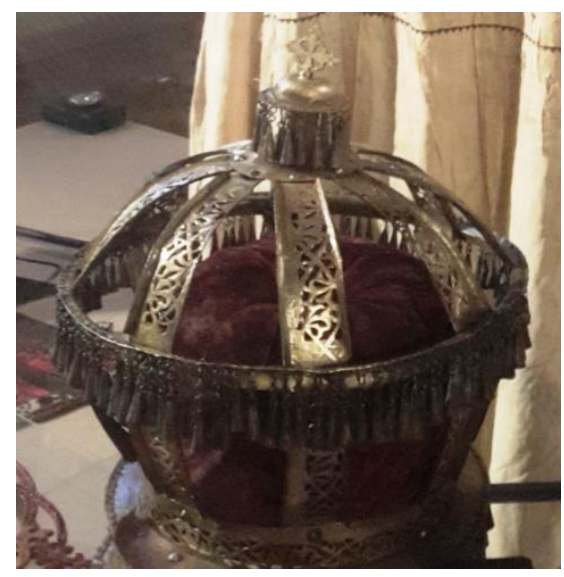

B

P1.19: (A) Le mitre éthiopien en bronze, enrichi par l'or et les pierres précieuses, au musée copte.( de

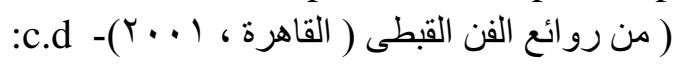

Pl.20: (B) Le mitre d'évêque en bronze, avec une doublure de velours cramoisi exposé dans le musée copte.
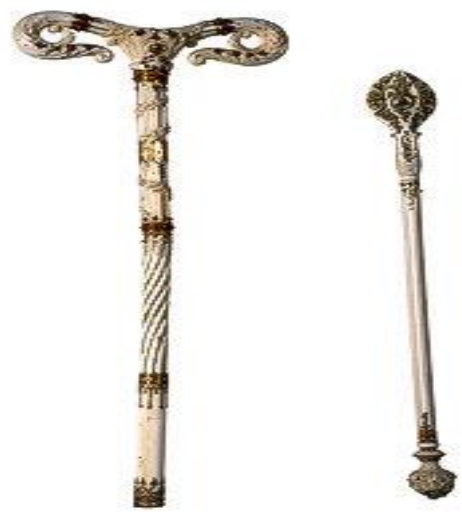

P1. 21: Le bâton pastoral en ivoire. (www.eternalegypt.org). 


\section{Les références}

${ }^{1}$ Vasileios Marinis, "Wearing the Bible. An early christian Tunic with New Testament scenes, " in: JCoptstud 9, Peeters press (Louvain , 2007), 95; Marie-Hélène Rutschowscaya, "Textiles-coptic," in: CoptEnc, vol.7, Macmillan publishing company (New York, 1991), 2210.

2 Alexandra Lorquin, "Techniques des textiles coptes", dans: Egypte la trame de l'histoire- Textiles pharaoniques, Coptes et Islamiques (Italie, 2002), 83; سعاد ماهر، "الفن القبطى"، الجهاز الادارى للكتب الجامعية و المدرسية،

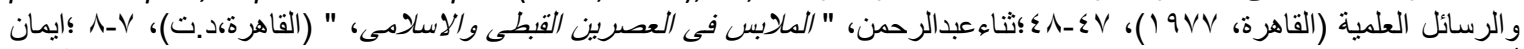

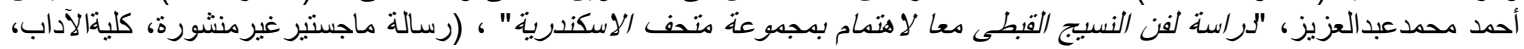

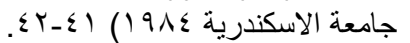

${ }^{3}$ Gawdat Gabra, "Le Caire- Le Musée Copte- Les Anciennes Eglises," traduit par : Hoda R. Khouzam et Marguerite Rassart- Debergh, Nubar printing house (Cairo, 2005), 45; ، ايمان عبدالعزيز، "دراسة لفن النسيج القبطى : " 7 .

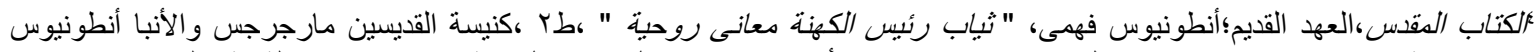

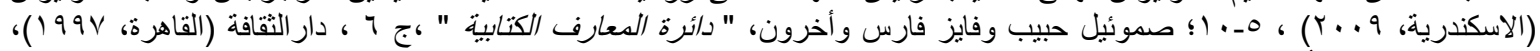

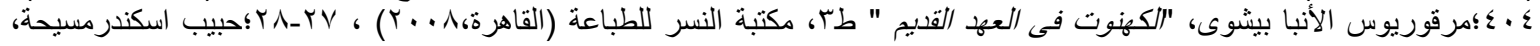

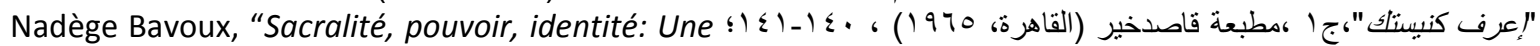
histoire du vêtement d'autel: (XIIlème-XVI ème siècles); (Thèse de doctorat, Université de Grenoble 2012),

46-47.

• عبدالفتاح محمد اسماعيل ندا، " اللباس الكهنوتى في مصرالفرعونية "، ( رسالة ماجستيرغيرمنشورة،كلية الآداب قسم التاريخ، جامعة

"Bavoux, "Une histoire du vêtement d'autel", 46.

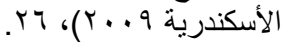

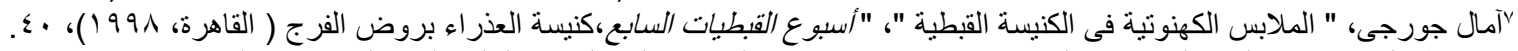

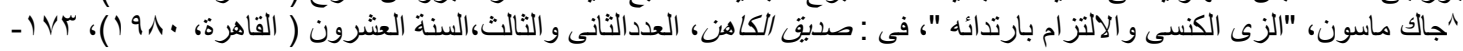
؛ V V \& Bavoux, "Une histoire de vêtement d'autel", 47 et 73; Nicole Gourdier, "Rite et vêtures d'Egypte, I'habit et son histoire", dans : Le monde copte, n.21-22, Dossier: Le monachisme égyptien ( La France,1993 ) 64.

"يسى عبدالمسيح، " الليتورجيات الشرقية - الملابس الكهنوتية " ،فى : مجلة الكرمة،الجزءالأول،السنة السابعة عشرة (القاهرة، يناير

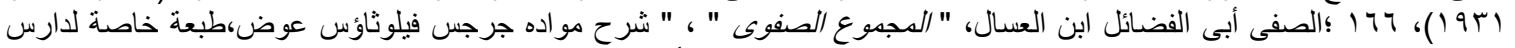

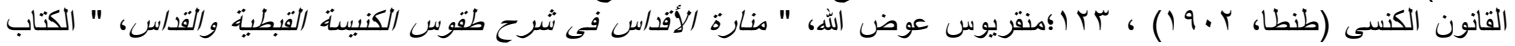

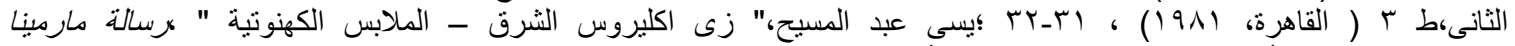

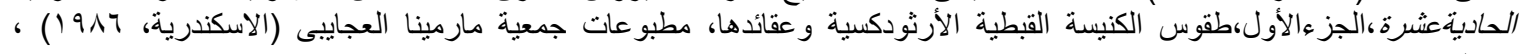

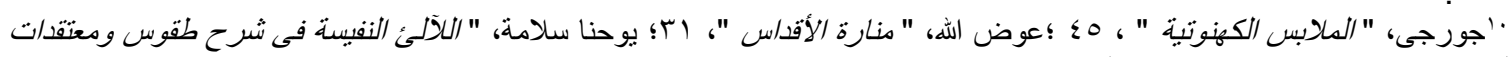

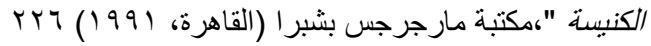

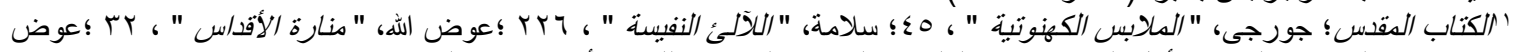

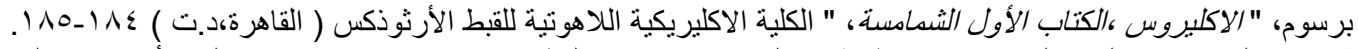

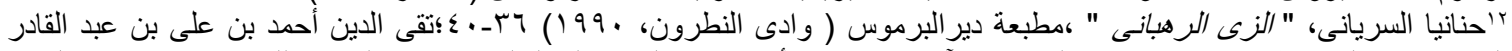

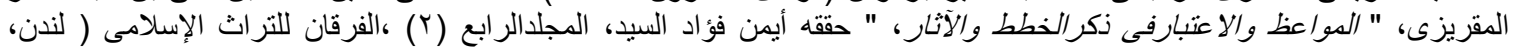

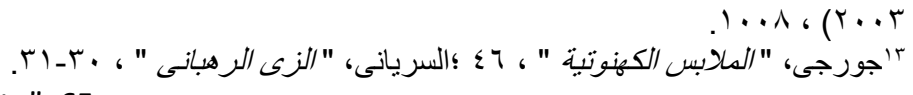

${ }^{14}$ Nicole Gourdier, "Rite et Vêtures d'Egypte", 65.

15 Sawiris Ibn El Muqaffa, " ترتبيالكهنوت ", Publications du centre d’Etudes orientales de la Custodie Fransiscaines de Terre-sainte, Coptica, Julius Assfalg (Le Caire, 1955), 32.

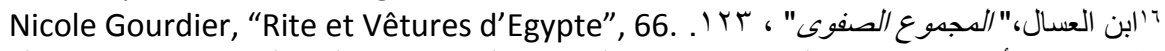

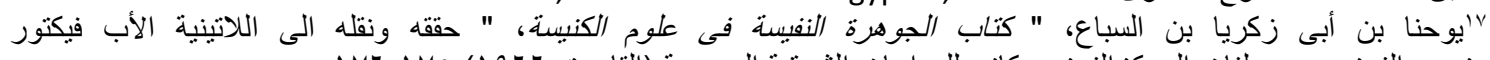

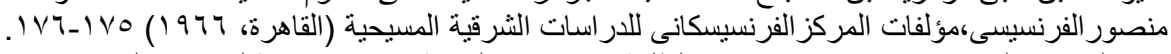

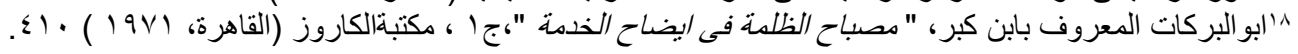

19 O.H.E Burmester, "The Rite of Consecration of the Patriarch of Alexandria" (Le Caire, 1960) 49-57;

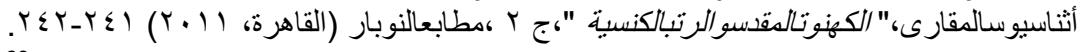

20 Paul Van Moorsel, “Les Peintures du Monastère de Saint-Antoine”, vol. I, Institut Français d'Archéologie orientale (Le Caire, 1992), 50; O.H.E Khs Burmester, "The Egyptian or Coptic Church-A detailed description of her liturgical services and the rites and ceremonies observed in the administration of her sacraments,

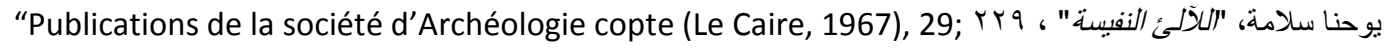




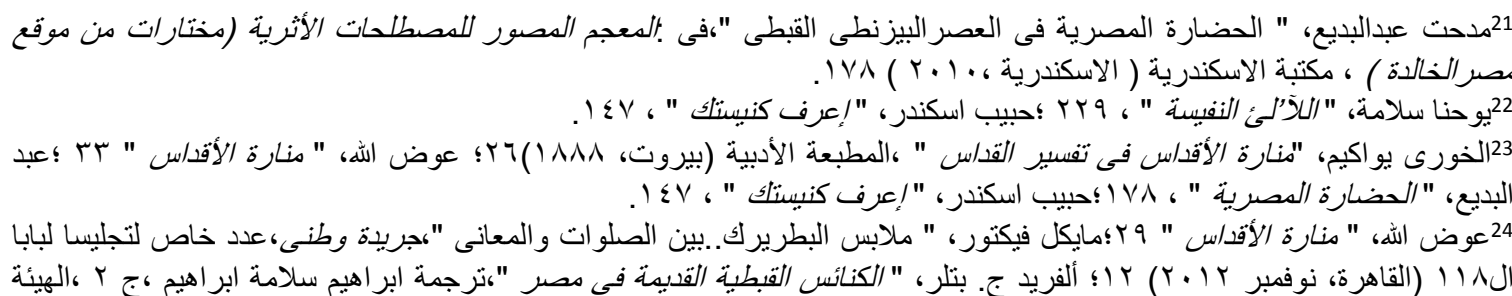

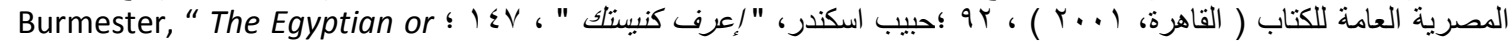
Coptic church, " 29; Nicole Morfin Gordier, " Costumes of the religious, " in : CoptEnc, vol. 2, Macmillam publishing company ( New York, 1991) 652; Basilios, "Liturgical vestments," in : : CoptEnc , vol. 5, Macmillam publishing company ( New York, 1991), 1478; Karl C. Innemée," Ecclesistical dress in the medieval Near East," , E.J. Brill (Leiden- New York - Kohn, 1992) 45.

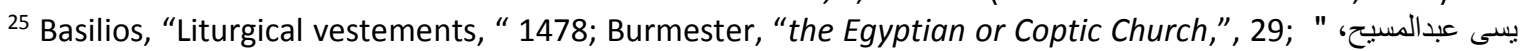

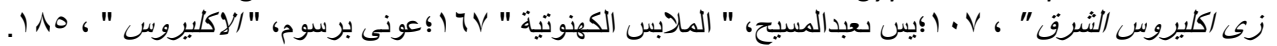

${ }^{26}$ Moorsel, "Les Peintures du Monastère de St. Antoine", 50.

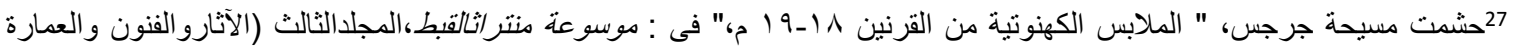

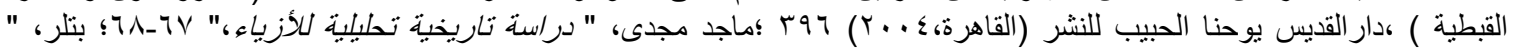

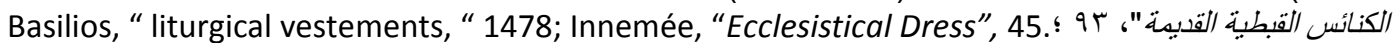

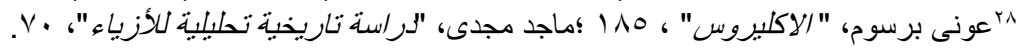

${ }^{29}$ Visite sur le champ.

${ }^{30}$ Visite sur le champ; le site officiel du musée national d'Alexandrie : www.alexmuseum.gov.eg.

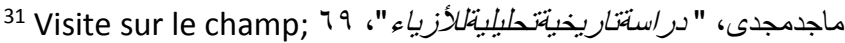

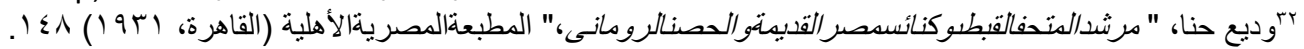

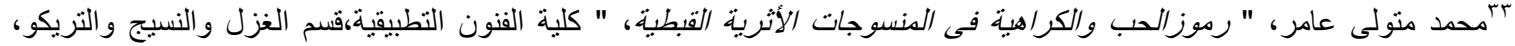

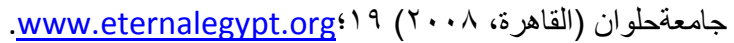

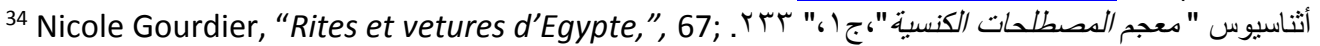

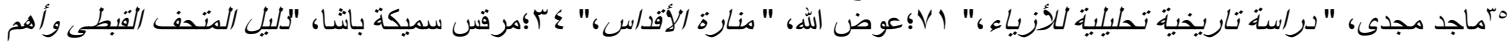

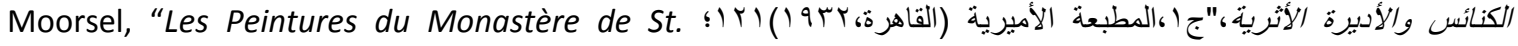
Antoine", 57.

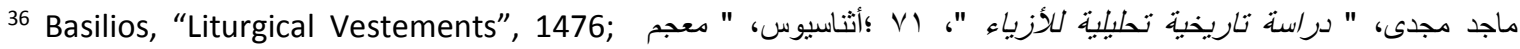

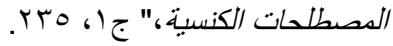

37 Claude Traunecker, “L'étole Diaconale Copte et ses antécédents, “Cahiers de la Bibliothèque copte 3, deuxième journée d'études coptes (Strasbourg, 1984), 107; Moorsel, "Les Peintures du Monastère de St Antoine", 58-59; Basilios, "Liturgical Vestements", 1477.

38 Innemée, "Ecclesiastical Dress," 46.

39 Basilios, "Liturgical Vestements, “ 1477; William H. Tadros, "Pas à pas dans la liturgie divine," Eglise

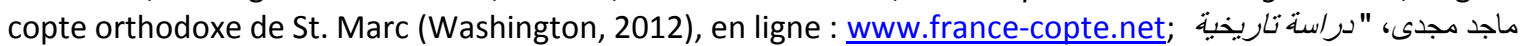

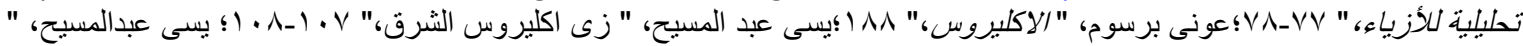

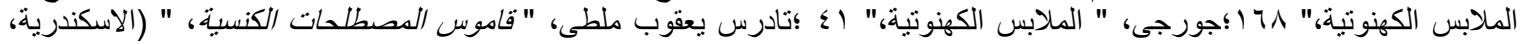
rv (1919r

40 Basilios, "Liturgical Vestements," , 1477; Moorsel, "Les Peintures du monastère de St. Antoine". 59;

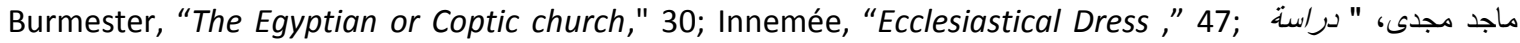

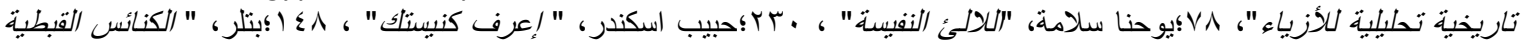

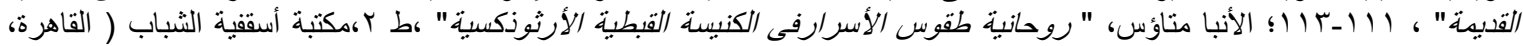
$.194-19 \cdot(1990$

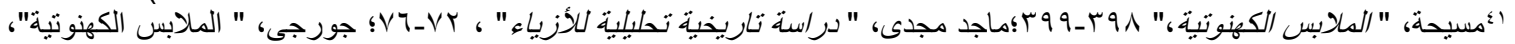

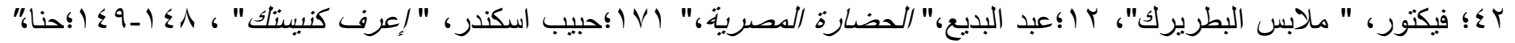

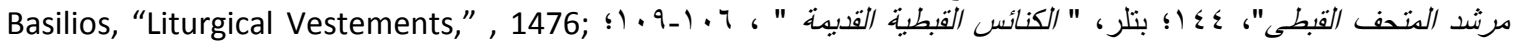
Burmester, "The Egyptian or Coptic church", 29.

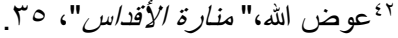

${ }^{43}$ Basilios, "Liturgical Vestements," 1476; Moorsel, "Les Peintures du monastère de St. Antoine". 58;

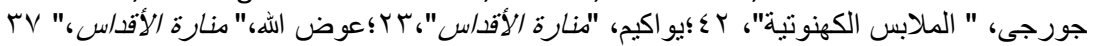

44 Visite sur le champ; le site officiel du musée: http://antiquites-bibalex.org. 
حنا،" مرشد ; Visite sur le champ; le site officiel du musée national d'Alexandrie: www.alexmuseum.gov.eg المتحف القبطى، "

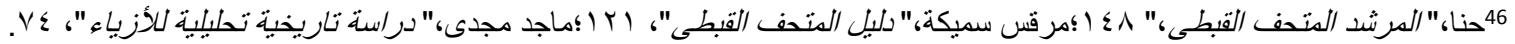

47 Visite sur le champ au musée copte.

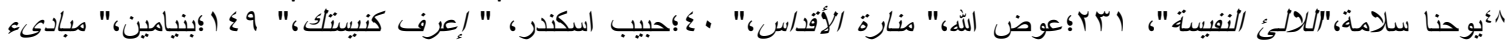

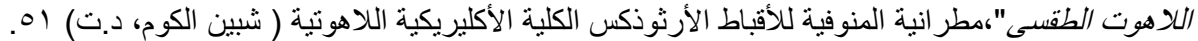

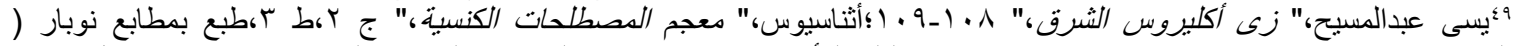

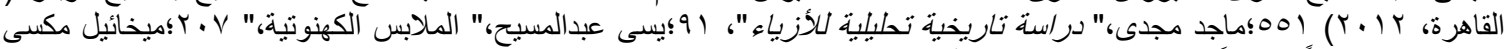

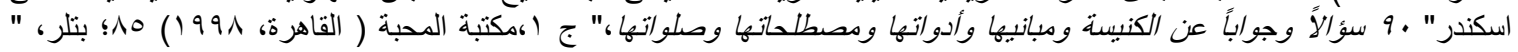

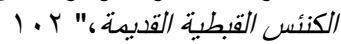

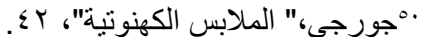

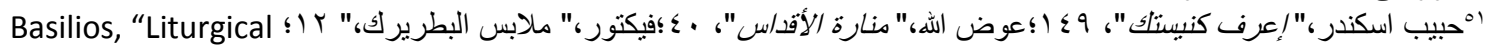
Vestements," , 1476; Burmester, "The Egyptian or Coptic church", 30.

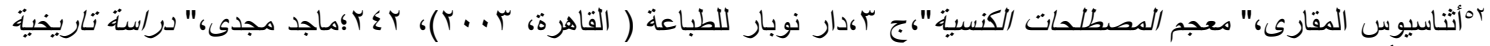

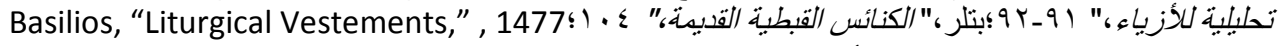

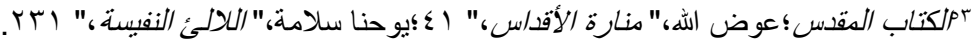

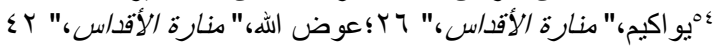

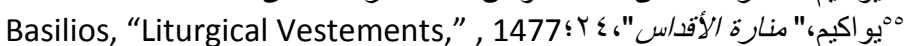
56 R.G.Coquin," A propos des vêtements des moines egyptiens, " BSAC, Tome XXXI ( Le Caire, 1992) 16-20;

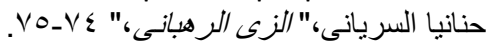

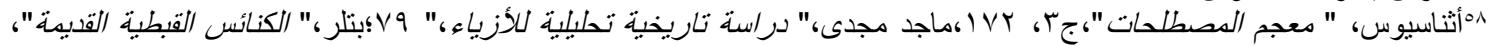

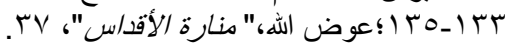

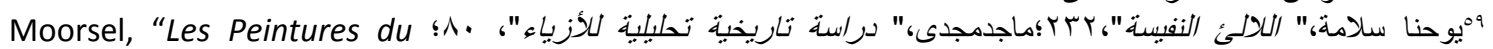
monastère de St. Antoine",59.

60 Basilios, “Liturgical Vestements," 1477 ; Burmester, “The Egyptian or Coptic church", 29; مسيحة،" الملابس "

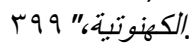

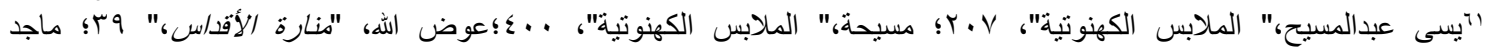

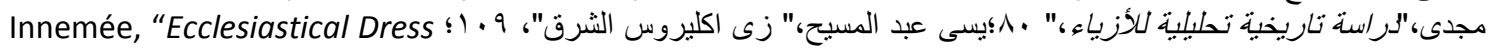
, 58

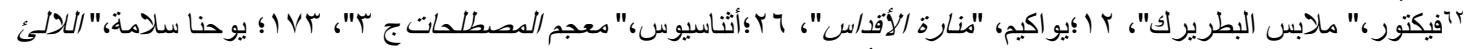

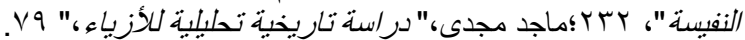

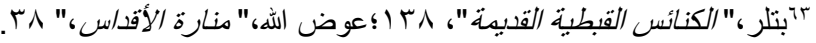

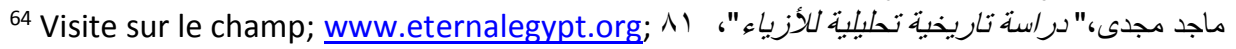

65 Visite sur le champ; 1 بتلر، 'الكنائس القبطبة القدبية "،

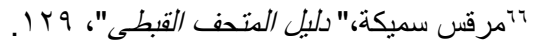

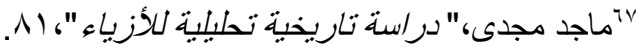

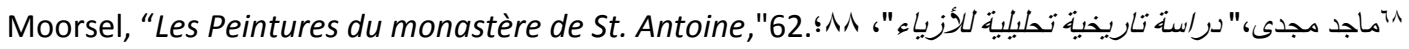
69 Basilios, "Liturgical Vestements," 1477; Moorsel, "Les Peintures du monastère de St. Antoine," 53-62;

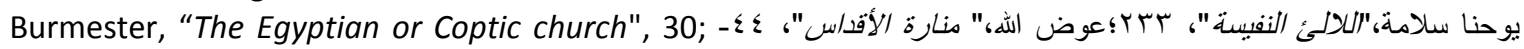

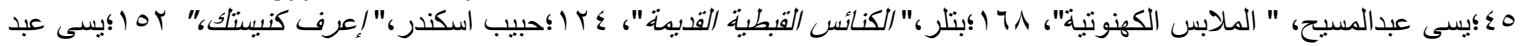

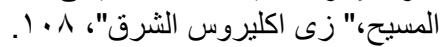

70 Innemée, "Ecclesiastical Dress," 52.

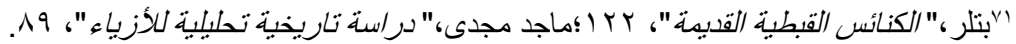

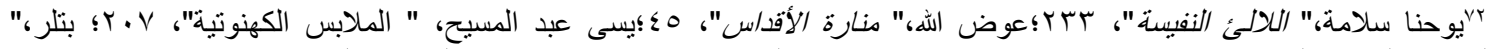

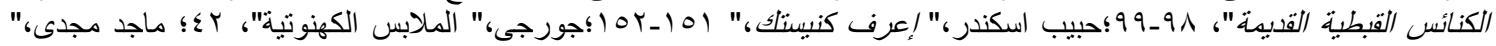

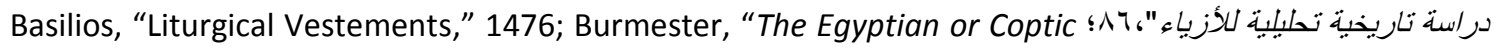
church", 29;Innemée, "Ecclesiastical Dress ," 56.

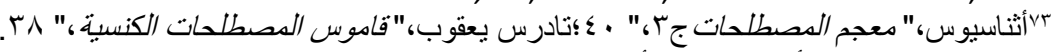

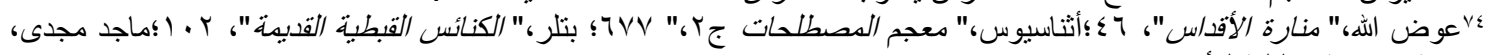

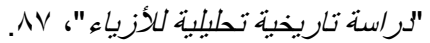

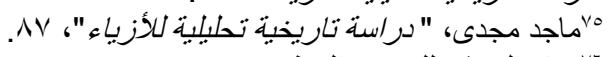

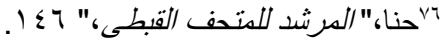


77 Basilios, "Liturgical Vestements," 1476; Moorsel, "Les Peintures du monastère de St. Antoine," 60-

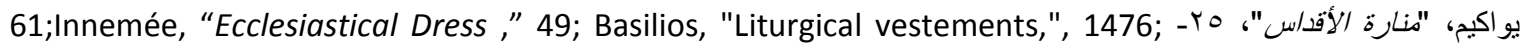

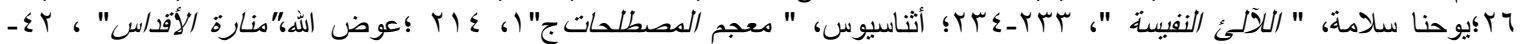

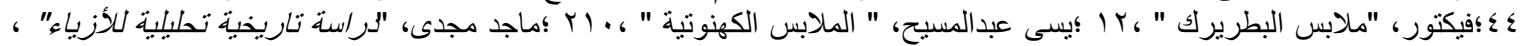
.Ar-Ar

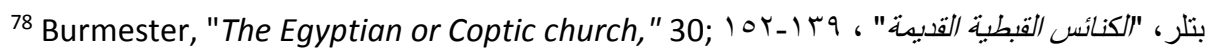

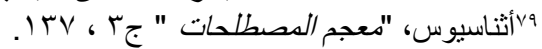

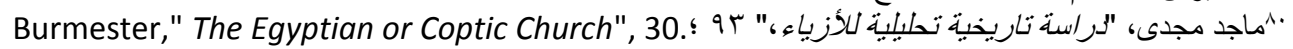

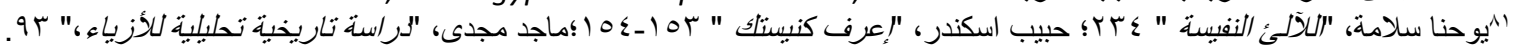

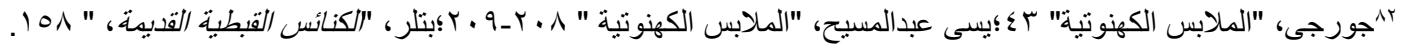

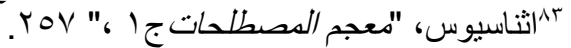

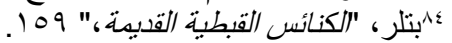

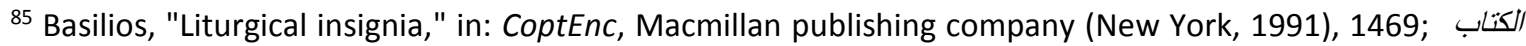

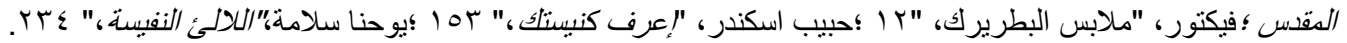

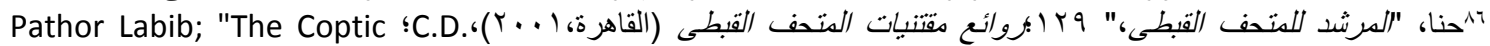
Museum and the forteress of Baylon, "Rhakoti, fourth year, AUC Press (Cairo, 2007)36.

88 Visite sur le champ; روائع مقتنيات المتحف القبطى CD

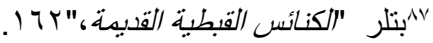

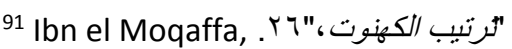

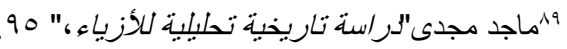

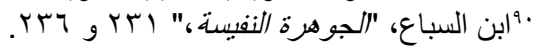

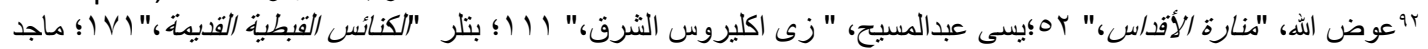

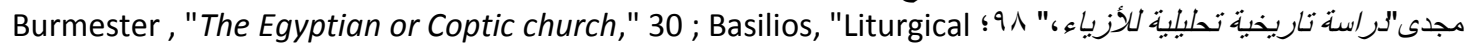
insignia," 1468.

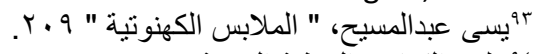

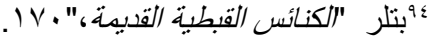

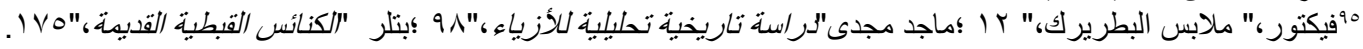
${ }^{96}$ www.eternalegypt.org

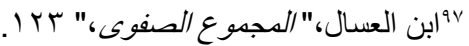

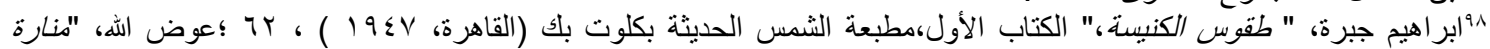

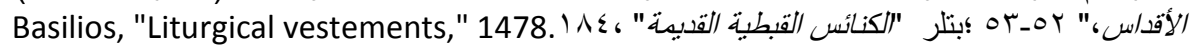

99 Basilios, "Liturgical Instruments, " in: CoptEnc, macmillan publishing company (New York, 1991 ), 1472;

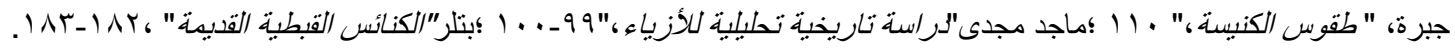

